\title{
Advancing Dental Education in the 21st Century: Phase 2 Report on Strategic Analysis and Recommendations
}

\author{
Allan J. Formicola, Howard L. Bailit, Jane A. Weintraub, \\ Jacquelyn L. Fried, Peter J. Polverini \\ Abstract: In Phase 1 of the "Advancing Dental Education in the 21st Century" project, research was conducted and published on \\ a number of serious challenges facing dental and allied dental education, both presently and projected to 2040 . Those findings \\ informed the strategic analysis and recommendations developed in Phase 2 of the project. This report provides an overview of \\ the Phase 2 conclusions and presents recommendations to address the challenges identified. The recommendations propose ways \\ to educate a workforce prepared to meet the oral health needs of the population; develop a sustainable economic model that \\ allows schools to meet their education, research, and service missions; make dental and allied dental education and practice an \\ integral part of the larger health education and delivery systems; and keep dentistry advancing as a "learned" profession. This \\ report begins with an Executive Summary and then presents the strategic analysis of challenges facing dental schools and allied \\ dental programs and provides a brief explanation of the rationale for each recommendation. Two appendices are included with \\ the report: the first summarizes discussions held at the national conference to consider the recommendations; and the second \\ provides additional documentation of calculations used to estimate the number of new dental graduates needed in 2040.
}

Allan J. Formicola, DDS, MS, is Dean Emeritus and Professor Emeritus, Columbia University College of Dental Medicine; Howard L. Bailit, DMD, PhD, is Professor Emeritus, Department of Community Medicine, School of Medicine, University of Connecticut; Jane A. Weintraub, DDS, MPH, is Alumni Distinguished Professor and former Dean, University of North Carolina at Chapel Hill School of Dentistry; Jacquelyn L. Fried, RDH, MS, is Associate Professor, University of Maryland School of Dentistry; and Peter J. Polverini, DDS, DMSc, is Jonathan Taft Distinguished University Professor and Dean Emeritus, University of Michigan School of Dentistry. Direct correspondence to Dr. Allan J. Formicola, Dean Emeritus, Columbia University College of Dental Medicine, 630 West 168th Street, New York, NY 10032; ajf3@cumc.columbia.edu.

Keywords: dental education, allied dental education, patient-centered care, integrated care, financing clinical education, medicine, research, interprofessional education

doi: 10.21815/JDE.018.109

\section{CONTENTS}

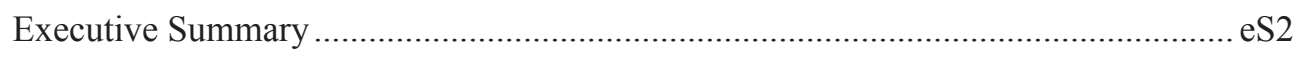

Phase 2 Report on Strategic Analysis and Recommendations ...................................eS5

Strategic Analysis of Challenges Facing Dental Schools ......................................S8

Strategic Analysis of Challenges Facing Allied Dental Programs.................... eS14

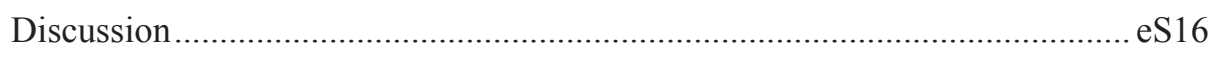

Conclusion: Guiding Principles .................................................................eS18

Appendix 1: Workshop Reports from the National Conference ...............................eS22

Appendix 2: Number of New Dental Graduates Needed in 2040 .............................eS31 


\section{EXECUTIVE SUMMARY}

$\mathrm{P}$ hase 1 of the "Advancing Dental Education in the 21st Century" project, launched in 2015, commissioned 37 background articles and six executive summaries of those articles, all of which were published with and in the August and September issues of the Journal of Dental Education in 2017. Those articles informed the strategic analysis and recommendations developed in Phase 2 of the project. This report provides an overview of the Phase 2 conclusions regarding serious long-range challenges that face dental and allied dental education, and it lays out practical strategies to address them over the next 25 years. The report's recommendations propose ways to educate a workforce that is prepared to meet the oral health needs of the population; develop a sustainable economic model that allows schools to meet their education, research, and service missions; make dental and allied dental education and practice an integral part of the larger health education and delivery systems; and keep dentistry advancing as a "learned" profession.

\section{Challenges Facing Dental Schools}

Outdated financial and educational models.

The current system of financing dental education is unsustainable, with much of the economic burden falling on students. The trajectory of rising education costs must be reversed. The reliance on dental schoolbased teaching clinics is largely to blame for the high cost of dental education. Insufficient curricular time devoted to evidence-based care and overall health, underinvestment in the recruitment of diverse faculty and students and in faculty development, and limited access to postdoctoral education also demand attention. The project's recommendations are as follows:

- Move from a student-centered to a patient-centered model of care to transform the economics of clinical education.

- Increase federal and state subsidies for safety net care.

- Strengthen and integrate teaching of the clinical, biomedical, population health, and behavioral sciences.
- Invest in developing a well-qualified and diverse faculty for full-time academic careers and recruit a diverse student body.

- Increase diversity of thought in the accreditation process.

Shrinking demand for dental services. With the opening of 13 new dental schools since 1990 and enrollment expansion at established schools, the number of graduates has grown faster than the population. During this same period, improvements in the oral health of the U.S. population have slowed growth in the demand for dental care, as has the lack of any major expansion of public or private dental insurance coverage. The project's recommendations are as follows:

- Downsize dental education.

- Increase integration with medical and other health professions schools.

Shifting practice environment. Each year, a larger portion of dental school graduates choose group over solo practices. Over time, group practices are expected to consolidate, and some will become part of large, integrated medical organizations. At the same time, more dentists will work in community-based (e.g., schools, workplace) satellite clinics run by large groups. Yet, most dental schools and graduate programs continue to prepare students first and foremost for independent, solo general or specialty practice. The project's recommendations are as follows:

- Move more clinical education to patient-centered delivery settings.

- Prepare students to manage the care of children and treat patients with complex dental and health care needs.

- Increase the integration of dental and medical education and practice (interprofessional education).

- In the longer term, integrate dental postdoctoral programs into the overall system of U.S. residency education.

- Welcome and facilitate basic oral health education for other health professionals. 
Insufficient support for research. A growing portion of the nation's dental schools are not based in research-intensive universities, and the majority of National Institutes of Health (NIH) research support to dental schools goes to only 13 institutions. Few full-time dental clinical faculty members have the scientific training to compete successfully for research grants, putting dentistry at risk of losing its status as a learned profession. The project's recommendations are as follows:

- Make research a core mission.

- Recruit research faculty members.

- Increase support for early-stage researchers and students.

- Place increased emphasis on interdisciplinary and collaborative research.

- Address the structural barriers to developing strong research programs.

- Strengthen CODA research standards for dental schools.

\section{Challenges Facing Allied Dental Programs}

The four allied dental professions face serious, but somewhat different, challenges. The rise of digital technologies has placed the restorative dental technologist profession at a critical turning point. The expansion of the dental assistant role by some states and the extensive variations in state practice acts have left dental assisting education programs lagging and with wide variations. In addition, the majority of practicing dental assistants are either trained on-the-job or have attended non-accredited programs. In dental hygiene education, accreditation standards that do not differentiate between students in baccalaureate and associate degree programs nor promote advanced degrees threaten the profession's ability to seize opportunities for a broader scope of practice in a wider range of settings with flexible supervision requirements. Finally, the educational infrastructure is not yet in place to support the preparation of dental therapists, who are entering the provider mix in a growing number of states and tribal locations.

The project's recommendations for restorative dental technology education are as follows:

- Require four years of education for all CODAaccredited restorative dental technology programs.
- Move clinical education to digitally equipped, community-based care settings.

The project's recommendations for dental assisting education are as follows:

- Ensure that CODA-accredited dental assisting programs impart knowledge and skills that cannot be obtained on-the-job.

- Prepare graduates for tomorrow's work environments.

- Create opportunities for relevant credit transfers.

- Work to create more standardization among state practice acts.

The project's recommendations for dental hygiene education are as follows:

- Transition to the baccalaureate degree for entry into practice.

- Prepare students for emerging practice environments.

- Develop educational pathways for dual dental hygiene-dental therapy degrees.

- Develop additional educational pathways for dental hygienists interested in academics, research, industry, and public health careers.

- Invest in developing diverse faculty for full-time academic careers.

- Increase dental hygienists' role in regulating dental hygiene education and practice.

The project's recommendations for dental therapy education are as follows:

- Increase the availability of dental therapy education.

- Respect local variation and flexibility in dental therapy education models as the field develops.

\section{Discussion}

To ensure the sustainability of dental education and prepare dental professionals for the evolving practice environment, dental schools should increase integration with medical and other academic health science center schools; reduce class size to realign the dental workforce with utilization trends; transform clinical education to cover most of its costs; and invest in full-time, tenure-track faculty members who are clinician-scientists with advanced science training, including at the $\mathrm{PhD}$ level, to compete for research support. Changing allied dental education programs to adapt to delivery system trends will require changes in accreditation standards and licensing 
requirements in addition to curricular changes that reflect expanding scopes of practice.

Although this report's recommendations apply to all U.S. schools and programs, they must be viewed in relation to each institution's local environment. Schools and programs will use different approaches to consider and possibly implement these recommendations and adapt them to scientific, peda- gogic, demographic, social, and public health trends. Some institutions are now carrying out many of this report's recommendations, suggesting the feasibility of implementing them at other schools and programs in the coming years. Although change is always difficult, there are many reasons to be optimistic about the future of dental education. 


\section{Phase 2 Report on Strategic Analysis and Recommendations}

I n 1926, Dr. William J. Gies, a professor of biochemistry at Columbia University, published Dental Education in the United States and Canada. ${ }^{1}$ Funded by the Carnegie Foundation, this landmark report was the result of Gies's five-year study of dental schools and the practice of dentistry at a time when dentists were educated largely through the proprietary apprenticeship model that dominated the era. Gies argued that, to best serve the oral health needs of the American people, dental schools should be based in research universities; dental students should receive the same foundation in the basic and clinical sciences that medical students received; and dentistry should be considered a specialty of medicine, though acknowledging that a full integration of medical and dental education was not feasible at the time.

The Gies report had a profound influence on dental education and, in turn, the dental profession. Many of its recommendations for reforming dental education were adopted, contributing to improved oral health for the nation's population and increasing respect for dentistry by placing it among the "learned" professions of theology, law, and medicine, which were traditionally associated with universitybased learning.

Subsequent studies, most notably Dental Education at the Crossroads: Challenges and Change, published by the Institute of Medicine (IOM) in $1995,{ }^{2}$ have examined the state of dental education and made recommendations. Other notable reports have emerged from the American Dental Education Association Commission on Change and Innovation in Dental Education (ADEA CCI), including the articles commissioned by the ADEA CCI, published in the Journal of Dental Education and collected in the 2010 volume Beyond the Crossroads, as well as the 2015 article "20 Years Beyond the Crossroads: The Path to Interprofessional Education at U.S. Dental Schools." ${ }^{3-5}$

Eight of the 17 major recommendations in the 1995 IOM report on dental education remain especially relevant today. ${ }^{2}$ They emphasize the need to move toward integrated basic science education for medical and dental students; require dental students to take at least one clerkship in medicine and give them opportunities for additional elective medical clerkships; provide students with clinical experiences in efficiently run, patient-centered dental delivery systems, working with experienced allied clinical and administrative personnel; make postdoctoral educational opportunities available to all students; encourage full-time, tenure-track faculty members to participate in research in collaboration with other university disciplines; rethink the basic model of dental education and develop less costly alternatives; expand the roles of and fully utilize allied dental professionals; and build a dental workforce that reflects the nation's diversity. Although some progress has been made in pursuing these recommendations, overall the IOM report has had limited influence on the core features of dental education, and until recently, schools have had little incentive to adopt its proposed solutions.

However, today, as the $21^{\text {st }}$ century unfolds, dental and allied dental education face new and serious challenges as historic market-driven pressures on the dental and medical delivery systems and advances in the science of oral health have begun to have a significant effect on dental education. As recently as 2007 , there were 2.8 applicants for every dental school slot, and dentists' incomes were rising. ${ }^{6,7}$ Since then, the economic picture has become less rosy for dentists, and by the 2014-15 academic year, the number of applicants relative to predoctoral program slots had contracted. Trends that were less evident one or two decades ago have become all too obvious. These delivery system and educational trends should create a greater sense of urgency and prompt schools to pay more attention to the IOM report's recommendations.

In response to these trends, a growing consensus has emerged that dental education needs to set a new course to adapt to contemporary challenges and opportunities, reflected in the "Advancing Dental Education in the $21^{\text {st }}$ Century" project. While building on and echoing many of the conclusions of earlier investigations, this project also brings new 
and compelling evidence to support the case for change. In Phase 1 of the project, launched in 2015, we invited 70 dental educators and other experts from across the U.S. to assess the state of dental education and the dental practice environment and consider likely trends through 2040. The project's leadership team began by posing several fundamental questions and assigning team leaders to oversee investigations into the issues these questions raised. Each section leader identified key issues to address and selected nationally recognized experts to prepare articles on these issues. These individuals produced 37 original background articles, which were published as supplements to the August and September 2017 issues of the Journal of Dental Education (Table 1; www. jdentaled.org/content $/ 81 / 8$ and www.jdentaled.org/ content/81/9). In addition, the section leaders (who are the authors of this report) prepared executive summaries of the articles in their sections, also published in those issues.

Table 1. Advancing Dental Education in the 21st Century, Phase 1 articles: research in response to fundamental questions

\begin{tabular}{|c|c|c|}
\hline Author/s & Title & Publication \\
\hline Bailit H, Formicola A & $\begin{array}{l}\text { Introduction to the "Advancing Dental Education in the 21st } \\
\text { Century" Project }\end{array}$ & Print \& online, Aug. 2017 issue \\
\hline \multicolumn{3}{|c|}{ What is the current state of dental schools with respect to their education and patient care programs? (Allan Formicola, Team Leader) } \\
\hline Formicola A & Current State of Dental Education: Executive Summary & Print \& online, Aug. 2017 issue \\
\hline Bailit H, Beazoglou T & Trends in Financing Dental Education, 2004-05 to 2011-12 & Online, Aug. 2017 supplement \\
\hline Kassebaum D, Tedesco L & $\begin{array}{l}\text { The 21st Century Dental Curriculum: A Framework for } \\
\text { Understanding Current Models }\end{array}$ & Online, Aug. 2017 supplement \\
\hline Formicola A & Ten-Year Student Trends in U.S. Dental Schools, 2004-05 to 2014-15 & Online, Aug. 2017 supplement \\
\hline Formicola A & $\begin{array}{l}\text { Considering Students' Cost of a Dental Education: Return on } \\
\text { Investment and Debt to Income Ratio }\end{array}$ & Online, Aug. 2017 supplement \\
\hline Formicola A & Trends in Dental Faculty of U.S. Dental Schools, 2003-04 to 2013-14 & Online, Aug. 2017 supplement \\
\hline Assael L & Current Status of Postdoctoral and Graduate Programs in Dentistry & Online, Aug. 2017 supplement \\
\hline Reinhardt J & Current Status of Operation and Management of Dental School Clinics & Online, Aug. 2017 supplement \\
\hline Lantz M, Shuler C & Trends in Basic Sciences Education in Dental Schools, 1999-2016 & Online, Aug. 2017 supplement \\
\hline Centore L & $\begin{array}{l}\text { Trends in Behavioral Sciences Education in Dental Schools, } 1926 \text { to } \\
2016\end{array}$ & Online, Aug. 2017 supplement \\
\hline Hamil L & $\begin{array}{l}\text { Looking Back to Move Ahead: Trends in Interprofessional Education } \\
\text { in Dental Education }\end{array}$ & Online, Aug. 2017 supplement \\
\hline Licari F, Evans C & Clinical and Community-Based Education in U.S. Dental Schools & Online, Aug. 2017 supplement \\
\hline Bailit H & Are Dental Schools Part of the Safety Net? & Online, Aug. 2017 supplement \\
\hline
\end{tabular}

How many dentists will be needed in 2040 to meet the effective demand for dental care? (Howard Bailit, Team Leader)

\begin{tabular}{|c|c|c|}
\hline Bailit H & How Many Dentists Are Needed in 2040: Executive Summary & Print \& online, Aug. 2017 issue \\
\hline Rozier G, White A, Slade G & Trends in Oral Diseases in the U.S. Population & Online, Aug. 2017 supplement \\
\hline Eklund S & $\begin{array}{l}\text { The Impact of Improved Oral Health on the Utilization of Dental } \\
\text { Services }\end{array}$ & Online, Aug. 2017 supplement \\
\hline Gesko D, Bailit H & Dental Group Practice and the Need for Dentists & Online, Aug. 2017 supplement \\
\hline Milgrom P, Horst J & The Effect of New Oral Care Technologies on the Need for Dentists & Online, Aug. 2017 supplement \\
\hline Manski R, Meyerhoefer C & Projecting the Demand for Dental Care in 2040 & Online, Aug. 2017 supplement \\
\hline Eklund $\mathrm{S}$, Bailit $\mathrm{H}$ & Estimating the Number of Dentists Needed in 2040 & Online, Aug. 2017 supplement \\
\hline
\end{tabular}

How will the structure and organization of the dental delivery system change in the next 25 years, and what are the implications for dental workforce educational programs? (Howard Bailit, Team Leader)

Bailit H The Dental Delivery System in 2040: Executive Summary

Brown J

Catalanotto $\mathrm{F}$ Jones J, Snyder J, Gesko D,
Helgeson M
Future Organization of Oral Health Services Delivery: From 2012 to 2042

Expected Changes in Regulation and Licensure: Influence on Future Education of Dentists

Integrated Medical-Dental Delivery Systems: Models in a Changing Environment and Their Implications for Dental Education
Print \& online, Sept. 2017 issue

Online, Sept. 2017 supplement

Online, Sept. 2017 supplement

Online, Sept. 2017 supplement

(continued) 
Table 1. Advancing Dental Education in the 21st Century, Phase 1 articles: research in response to fundamental questions (continued)

\begin{tabular}{|c|c|c|}
\hline Author/s & Title & Publication \\
\hline \multicolumn{3}{|c|}{$\begin{array}{l}\text { What knowledge and skills should pre- and postdoctoral students have to provide dental care in } 2040 \text {, and how should educators } \\
\text { prepare them to meet this objective? (Jane Weintraub, Team Leader) }\end{array}$} \\
\hline Weintraub J & $\begin{array}{l}\text { What Should Oral Health Professionals Know in 2040: Executive } \\
\text { Summary }\end{array}$ & Print \& online, Aug. 2017 issue \\
\hline $\begin{array}{l}\text { Fontana M, Gonzalez- } \\
\text { Cabezas C, de Peralta T, } \\
\text { Johnsen D }\end{array}$ & $\begin{array}{l}\text { Dental Education Required for the Changing Health Care } \\
\text { Environment }\end{array}$ & Online, Aug. 2017 supplement \\
\hline Thierer T, Meyerowitz C & $\begin{array}{l}\text { Trends in Generalist and Specialty Advanced Dental Education and } \\
\text { Practice, 2005-06 to 2015-16 and Beyond }\end{array}$ & Online, Aug. 2017 supplement \\
\hline Silk H & $\begin{array}{l}\text { The Future of Oral Health Care Provided by Physicians and Allied } \\
\text { Professionals }\end{array}$ & Online, Aug. 2017 supplement \\
\hline Glick M, Greenberg B & $\begin{array}{l}\text { The Role of Oral Health Care Professionals in Providing Medical } \\
\text { Services }\end{array}$ & Online, Aug. 2017 supplement \\
\hline Andrews E & $\begin{array}{l}\text { The Future of Interprofessional Education and Practice for Dentists } \\
\text { and Dental Education }\end{array}$ & Online, Aug. 2017 supplement \\
\hline
\end{tabular}

What is the status of dental school research and scholarly activity, and how should these endeavors evolve over the next 25 years? (Peter Polverini, Team Leader)

Polverini P

Dental Research and Scholarship in 2040: Executive Summary

Print \& online, Sept. 2017 issue

D'Souza R

How Research Training Will Shape the Future of Dental, Oral, and Craniofacial Research

Lamster I, Myers-Wright N Oral Health Care in the Future: Expansion of the Scope of Dental Practice to Improve Health

McCauley L

The Future of Dental Schools in Research Universities and Academic Medical Centers

Polverini P, Krebsbach P

Research and Discovery Science and the Future of Dental Education and Practice

Slavkin $\mathrm{H}$

The Impact of Research on the Future of Dental Education: How Research and Innovation Shape Dental Education and the Dental Profession

Online, Sept. 2017 supplement

Online, Sept. 2017 supplement

Online, Sept. 2017 supplement

Online, Sept. 2017 supplement

Online, Sept. 2017 supplement

What is the current state of allied dental education programs, and what knowledge will these dental professionals need in 2040 ? (Jacquelyn Fried, Team Leader)

Fried J

The Allied Dental Professions in 2040: Executive Summary

Print \& online, Sept. 2017 issue

Kracher C, Breen C,

The Evolution of the Dental Assisting Profession

Online, Sept. 2017 supplement

McMahon K, Gagliardi L,

Miyasaki C, Landsberg K,

Reed C

Westphal Theile C

Strengths and Weaknesses of the Current Dental Hygiene Educational System

Online, Sept. 2017 supplement

Fried J, Maxey $\mathrm{H}$, Battani

K, Gurenlian J, Byrd T, Brunick A

Preparing the Future Dental Hygiene Workforce: Knowledge, Skills, and Reform

Maxey $\mathrm{H}$, Farrell $\mathrm{C}$, Gwozdek A

Exploring Current and Future Roles of Non-Dental Professionals: Implications for Dental Hygiene Education

Bobich A, Mitchell B

Transforming Dental Technology Education: Skills, Knowledge, and Curricular Reform

Brickle C, Self K

Dental Therapists as New Oral Health Practitioners: Increasing Access for Underserved Populations

Online, Sept. 2017 supplement

Online, Sept. 2017 supplement

Online, Sept. 2017 supplement

Online, Sept. 2017 supplement

Note: To access articles, go to www.jdentaled.org/content/81/8 for August articles and www.jdentaled.org/content/81/9 for September articles and scroll down to "Advancing Dental Education in the $21^{\text {st }}$ Century" sections of table of contents. 
These articles informed Phase 2 of the project: the strategic analysis and recommendations presented in this report. In Phase 2, the section leaders worked together to prepare a report with a set of recommendations designed to strengthen the existing dental education system. The draft report was reviewed by selected authors of the Phase 1 articles and other knowledgeable individuals chosen by the project directors, and the "Advancing Dental Education in the $21^{\text {st }}$ Century National Conference" was subsequently held at the Rutgers School of Dental Medicine on June 27-28, 2018, to discuss the report. Five workshops were held at the conference to discuss the report's recommendations. Summaries of the discussions and additional recommendations that emerged in those workshops appear in Appendix 1.

The goal of the Phase 2 analysis was to develop recommended practical strategies for all types of dental education programs - predoctoral, advanced, and allied - to address long-range challenges related to finances, curriculum, research, and diversity. This report's recommendations propose ways to:

- educate a workforce that is prepared to meet the oral health needs of the population;

- develop a sustainable economic model that allows schools to meet their education, research, and service missions;

- make dental and allied dental education and practice an integral part of the larger health education and delivery systems; and

- keep dentistry advancing as a learned profession.

Overall, this report endeavors to lay out the basis for a strategic plan that will guide dental education for the next 25 years.

\section{Strategic Analysis of Challenges Facing Dental Schools}

Phase 1 of the project identified a series of challenges facing dental education. Some institutions have already taken steps to address one or more of the identified challenges. We hope that all dental schools will follow their lead and seriously consider adopting the recommendations that follow for the health of our profession and our institutions. Our analysis and the recommendations that emerged are organized into four general areas of challenges: financial and educational models, demand for dental services, support for research, and knowledge needed for the shifting practice environment.

\section{Outdated Financial and Educational Models}

Based on our analysis, the current system of financing dental education is unsustainable and restrains schools' ability to control the costs of education and invest in necessary program improvements. Over the past 20 years, public dental schools have lost, on average, $40 \%$ of state revenues. ${ }^{7}$ Private and public schools now charge substantially higher tuition and fees than in the past to cover operating costs, which places a greater financial burden on students. In response, public and private schools have filled the funding gap by increasing enrollments, raising tuition and fees, initiating high-cost international dentist programs, underinvesting in physical facilities and support systems, reducing the basic science faculty, forgoing the addition of clinical faculty members to keep pace with higher enrollments, and employing more part-time faculty members.

Educating dentists in academic dental institutions has been inherently more expensive than educating other health professionals for one central reason: dental schools own and operate their own clinics as student-centered teaching laboratories. These clinics require large subsidies from dental schools and limit students' clinical experiences in terms of both number and type of patients (e.g., children, older adult, rural, culturally diverse, patients with special needs). ${ }^{7,8}$ This clinical training is rarely publicly subsidized despite the fact that dental school clinics are an important component of the dental safety net, providing comparable services to publicly subsidized Federally Qualified Health Centers (FQHCs). ${ }^{9}$

Most of the economic burden of dental education falls on the students. In 2015, dental school graduates' educational debt averaged roughly $\$ 250,000$. $^{7}$ There will likely be a limit to how much students will be willing to borrow to finance their education, especially as dentists' incomes continue to grow slowly. ${ }^{10}$ Students from low-income families are especially challenged by rising costs and have declined as a proportion of entering students. ${ }^{7,11}$ The influence of student debt is also reflected in the reluctance of dental school graduates to take on additional debt. Only $5 \%$ of graduates purchase or start new practices, and approximately $60 \%$ choose on-the-job training at their first place of employment rather than in accredited postdoctoral programs. ${ }^{11}$

Dental schools face three other hurdles that affect their ability to meet their educational missions. Because predoctoral programs are required to prepare 
students for independent practice at the end of four years, their curricula are overcrowded, inflexible, and mainly focused on restorations, limiting educators' ability to adapt both content and pedagogy to scientific and technologic advances and to societal changes. ${ }^{12,13}$ The overcrowded curricula do not permit adequate emphasis on important content areas such as care of children and patients with special health care needs, evidence-based dentistry, and analytic skills.

Schools also face a wave of faculty retirements as baby-boomers age out of the workforce. At the same time, educational debt is pushing some younger dentists, even those with advanced clinical and scientific training, to seek more lucrative private practice opportunities. ${ }^{14}$ Difficulty in obtaining research grants disillusions future research-oriented academics. These factors make it challenging to find qualified individuals to fill the faculty ranks.

A related issue is the scarcity of underrepresented minority (URM) faculty members, which makes it more difficult to recruit URM students. This scarcity is an urgent public health issue because minority dentists treat more low-income patients than do non-minority dentists. ${ }^{15-19}$ Currently, only $12 \%$ of dental students are from URM groups, and this percentage has not changed in the past 20 years - even though the total minority population is expected to exceed 50\% of Americans in 2043. ${ }^{11}$

The primary organization accrediting dental education programs, the Commission on Dental Accreditation (CODA), has a critical role to play in helping dental education change with the times. CODA has updated its standards to encourage more student diversity and to require that schools offer community-based experiences for students. ${ }^{20} \mathrm{Nev}$ ertheless, CODA's role is limited by the fact that its peer-review process establishes and enforces existing standards, making it difficult to advance significant changes in school programs and operations. Site visit committees that examine dental education programs should include members from outside of dental education to bring a diversity of thought to the accreditation process.

The project's recommendations for this area are as follows:

Move from a student-centered to a patientcentered model of care to transform the economics of clinical education. To generate adequate funds to meet their education, research, and service missions and to reduce the rate of tuition increases, dental schools need to change the basic model of clinical education. Following the model of other U.S. health professions, dental schools need to educate the oral health workforce in patient-centered delivery systems where faculty members practice as they supervise pre- and postdoctoral students. Unlike studentcentered clinics, whose primary goal is education, patient-centered delivery systems are organized primarily to deliver patient care effectively and efficiently by the experienced clinical faculty. In this model, reimbursement for services rendered covers faculty salaries and clinic overhead. Students also benefit from working in teams with faculty members, postdoctoral students, and other health professionals, and they gain substantially more clinical experience. All oral and maxillofacial surgery residents and most pediatric dentistry residents are educated in hospitals that largely use this approach. ${ }^{21}$

The shift to a patient-centered model can be accomplished in two ways. The first is to increase the time that students spend in community settings such as clinics, hospitals, and dental group practices. Almost all schools already have relationships with external clinics and can build on these existing relationships to move more clinical education to the community. The second approach is to operate some dental school clinics as patient-centered delivery systems, in which faculty, residents, students, allied personnel, and other health personnel practice together with the primary goal of patient care. Several schools now follow this model in school-based and satellite dental facilities that they own and operate.

Increase federal and state subsidies for safety net care. The important role that dental schools play in providing care to underserved populations should be leveraged to encourage additional public subsidies for dental education at the federal and state levels. Some states already offset low Medicaid reimbursement rates with supplemental payments to schools that file Medicaid cost reports. At least one dental school, at A.T. Still University in Missouri, has integrated its clinical operations with FQHCs, which receive higher Medicaid reimbursement rates. ${ }^{9}$ These and other mechanisms can reduce the economic burden of providing safety net care.

Strengthen and integrate teaching of the clinical, biomedical, population health, and behavioral sciences. Graduates' knowledge in the biomedical and behavioral sciences needs to be improved and integrated into their clinical training to strengthen their command of scientific knowledge as it applies to patient care. ${ }^{22-25}$ Schools also need to enhance their clinical science programs to better prepare students to care for children, older adults, and patients who have special needs and are medically compromised, who will make up an increasing share of the patient 
population in the next 25 years. ${ }^{26}$ In addition, graduates need to understand the bigger picture of social determinants of health and health disparities to be leaders in their communities to improve population health. Social workers, patient navigators, and electronic tools are becoming available to assist people and better coordinate their care.

Invest in developing a well-qualified and diverse faculty for full-time academic careers and recruit a diverse student body. To replace an aging faculty, targeted pipeline programs that support advanced formal education in pedagogy and research are needed to recruit and prepare oral health professionals interested in academic dental careers. ${ }^{27}$ Public and private grants and loan repayment opportunities will be needed to make academic careers more financially attractive. Schools also need to hire more faculty members from URM groups to bolster their ability to recruit more URM students. The methods for achieving these objectives are well known, and some schools can serve as models for attracting a diverse student body. ${ }^{15}$ Leadership at the university and dental school levels will be needed to ensure that all dental schools achieve these goals.

Increase diversity of thought in the accreditation process. CODA needs more outside input into the accreditation process. Site visit teams are comprised of individuals drawn from the dental education programs that CODA accredits. To encourage dental schools to embrace fundamental changes and move in new directions, inclusion of site visit team members from the other health professions and beyond would bring diversity of thought into the accrediting process. Doing so would allow CODA to better serve society and all of the accredited dental education programs.

\section{Shrinking Demand for Dental Services}

Static middle-class incomes, a decline in private dental insurance and service utilization by working adults, and improvements in oral health-especially among higher income populations that account for about $65 \%$ of private practice revenues - have all contributed to a slowdown in the growth of per capita demand for dental care. ${ }^{28,29}$ With less demand, utilization rates for common restorative, surgical, and prosthetic services by privately insured patients have declined $30 \%$ to $50 \%$ over the past 20 years. ${ }^{30}$ At present, about $75 \%$ of dental visits by privately insured patients are for diagnostic and preventive services, and this percentage is increasing about $1 \%$ per year. ${ }^{31}$ Demand is likely to slow further as the population's oral health continues to improve and as the generation that came of age before the widespread availability of fluoride becomes a smaller percentage of practice patients. ${ }^{30}$ The growing use of implants is not expected to appreciably affect this general decline in restorative and prosthetic services. ${ }^{32}$

While demand has been shrinking, new dental schools have been opening their doors-13 since 1990 - and many established schools have increased their enrollments. As a result, the number of graduates grew from 4,300 in 2002 to 6,000 in $2015 .{ }^{11}$ The growth in dental school enrollment appears to be leveling off, but, so long as the number of graduates remains at current rates, the number of clinically active dentists is expected to increase from 195,000 in 2013 to about 240,000 in 2040 (adjusted for age and gender 213,000). ${ }^{11,33,34}$

With the recent increase in the number of dentists entering the workforce and slow growing demand for dental services, the average income of general practitioners has declined from $\$ 213,000$ in 2008 to $\$ 179,000$ in 2015 , and $35 \%$ of solo dentists reported in 2015 not being busy enough..$^{35}$ The availability of dental services is also increasing with the growth of large, capitated group dental practices that operate more efficiently than traditional solo practices. Based on data from one dental group, general practitioners cared for an average of 2,100 patients annually as compared to 1,350 patients each year on average by solo practice general dentists. ${ }^{36}$

Researchers estimate that 100 million lowincome adults have problems accessing dental care because they lack the means to pay for it and face related transportation, language, or educational barriers. ${ }^{37}$ Demand would increase if Medicaid provided adult coverage, better benefits, and higher reimbursement rates in all states, but recent history suggests there is little likelihood this will happen in the foreseeable future. Similarly, Medicare does not cover dental care except for a limited number of "medically necessary" dental procedures. Although efforts are under way to add a Medicare dental benefit for patients with specific diseases such as diabetes, planners cannot assume that these efforts will succeed and lead to increased demand for dental services in the next 25 years.

Demand for dental services is also being shaped by changes in the management of dental caries. Demineralization in the enamel, lesions in the outer third of the dentin, and even cavitated lesions in the dentin can be treated by nonsurgical means that arrest 
the demineralization process and increase remineralization. ${ }^{38}$ New restorative materials will continue to become stronger and more biocompatible. ${ }^{39}$ These advances will likely lead to a further reduction in demand for surgical interventions, while shifting more services to allied dental professionals. In many states, dental hygienists can legally provide most of the screening and preventive services needed by children and adults.

The potential growth in the number of dental therapists also needs to be factored into demand projections. It is too soon to predict the effect that dental therapists might have on the available national supply of dental services by 2040 , but it appears likely that their presence will expand in the coming decades. ${ }^{40}$ In Alaska, dental therapists are well established in remote Alaska Native communities, and tribal communities in Oregon began employing them in 2017. Advanced dental therapists and dental therapists are now legal providers practicing in Minnesota as well. Preliminary studies show that communities accept advanced dental therapists and dental therapists and that dental therapists and dentists provide restorative care of comparable quality. Maine and Vermont have recently passed legislation authorizing dental therapists, and several other states have legislation pending.

For all these reasons, the per capita effective demand for dentists' services will not keep pace with the growth in the dentist workforce. As care delivery becomes more efficient in the next 25 years, the average full-time general dentist and support staff will likely care for at least 2,000 patients per year. ${ }^{31}$ By 2040 , with a projected supply of 240,000 dentists for a population of 380 million, there will be approximately 168,000 full-time equivalent dentists to treat the 160 million people ( $42 \%$ of projected U.S. residents) expected to visit a dentist each year. ${ }^{29}$ If these projections prove true, a steady production of 3,000 to 4,000 new dentists per year (substantially fewer than the current annual figure of 6,000 graduates per year) will be adequate to meet the market demand for dental care in 2040 (see Appendix 2). ${ }^{31}$

These projections do not account for the unmet need resulting from a long-standing maldistribution of dentists. A portion of the predicted surplus could be absorbed by underserved areas and disadvantaged populations that need more dental care if the right incentives were put in place. Expanded public insurance coverage and higher reimbursement rates along with more scholarship and loan repayment programs could encourage more dentists to practice in under- served areas. Alternative delivery methods using telehealth could also engage dentists in alleviating inequities in access to care.

The project's recommendations for this area are as follows:

Downsize dental education. With the growing surplus of dentists, schools should reduce their class sizes in an orderly way before market forces spur a collapse of the applicant pool. First-year enrollments could be progressively reduced to bring the number of dental school graduates in line with the demand for care. Alternatively, schools can let the marketplace solve the impending dentist surplus, as happened in the 1980s. ${ }^{41}$ As market competition results in declining dentist incomes, fewer people will apply to dental school, especially with graduates' average educational debt climbing above $\$ 250,000$. $^{7}$ Taking the initiative to downsize in an orderly way before the collapse of the applicant pool and school closings is the preferable option. All academic health centers benefit from dental education and practice programs and from the integration of dental care as a core component of good health care.

Increase integration with medical and other health professions schools. Closer integration with medical and other health professions schools will enhance dental curricula and support the integration of oral and systemic health content in the curricula of all health professions programs. ${ }^{42}$ Closer school integration also has the potential to strengthen basic science and clinical programs and at the same time streamline administrative functions, increase operational efficiency, and help contain expenses.

\section{Shifting Practice Environment: Knowledge Needed in 2040}

Although some solo practices will continue to thrive, most likely in rural and high-income areas, each year a larger proportion of graduates are starting their careers in group practices. ${ }^{43}$ In time, these groups will consolidate in local markets, and some will become part of large integrated medical organizations. These environments are very different from solo practices and require new employees to have more medical knowledge and clinical experience. Nevertheless, most dental schools and graduate programs continue to prepare students primarily for independent solo practice in general or specialty dentistry.

More dental care in the future will also be provided outside the walls of dental offices-in schools, medical group practices, nursing homes, 
and other community settings, with many types of dental and medical providers delivering the care. ${ }^{44}$ As more dental group practices become part of large, integrated health care systems, closer coordination of patient care will be required among the various health professions. ${ }^{26}$ This is especially true for systems that are at financial risk for both medical and dental care. ${ }^{45}$

The patient population is also changing. Older pre-fluoride cohorts will continue to need maintenance and repair of restorative treatments provided earlier in life, but they are becoming a declining share of patients..$^{28}$ As oral health continues to improve, less time will be spent on the routine management of caries and the sequelae of untreated caries (e.g., prosthodontics). Instead, dental providers will spend more time managing patients with major medical illnesses that affect oral health.

In the longer term (beyond 2040), major changes can be expected in treatment modalities, from the wider use of $3 \mathrm{D}$ imaging and printing to new developments in robotics, stem cell and tissue engineering, and implants to replace partial or entire missing teeth. ${ }^{46}$ Other innovations that will affect the practice environment include the nonsurgical management of dental caries and periodontal diseases and the use of genomic and proteomic biomarkers to identify people who need specific preventive or other services.

These developments will affect both predoctoral and advanced dental education. The number and types of American Dental Association-recognized specialties are likely to evolve as disease trends change, more graduates enroll in residencies and other advanced education programs, and new treatment modalities replace those that currently dominate care. ${ }^{47}$ At the same time, the lack of federal Graduate Medical Education (GME) support for dental school-based advanced dental education programs and the magnitude of debt accumulated by students will continue to pose challenges. ${ }^{48}$

State dental practice acts will likely change to better accommodate the group practice delivery model. Policymakers will address issues such as the ownership of dental practices by non-dentists, the scope of practice and roles of allied dental and medical personnel, and licensure and credentialing requirements for U.S. and foreign-trained dentists. ${ }^{44}$ All these regulatory changes will have a profound effect on the role of dentists and, in turn, dental education.

The project's recommendations for this area are as follows:
Move more clinical education to patientcentered delivery settings, where teams of faculty, pre- and postdoctoral students, and allied dental and other health professionals deliver care. More experience in these settings will better prepare pre- and postdoctoral students to administer and provide care in the types of environments where they are likely to practice. $^{43}$

Prepare students to manage the care of children and treat patients with complex dental and health care needs. With more patients presenting with chronic and other conditions that affect their oral health, pre- and postdoctoral dental students need to know how to screen for and monitor common medical conditions. Graduates will also need more basic and clinical knowledge of medicine in order to interact effectively with other health professionals in the care of patients with significant medical problems. ${ }^{49}$

Schools can accomplish these goals by strengthening and integrating the basic, behavioral, and clinical sciences and by providing more clinical opportunities for delivering general and specialty dental care to patients with complex needs. Schools also should provide dental students with experience using shared medical and dental records and working with patient navigators to bridge the medical-dental divide. Ideally, all dental students should complete a biomedical science program integrated with a medical school, as well as a course in physical diagnosis and at least one medical outpatient rotation. Alternatively, some predoctoral and advanced education programs in general dentistry could develop tracks for students who want to provide more medical screening and monitoring for their patients. Such programs could establish an advanced dental degree or joint dental-medical degree indicating that dentists had gained such knowledge. ${ }^{49}$

Increase the integration of dental and medical education and practice (interprofessional education). More curricular time in dental schools needs to be integrated with medical and other health professions programs, so that graduates are prepared to collaborate effectively with other health professionals in the practice environments they will likely encounter. Student experiences should include opportunities to work with populations that are vulnerable and disadvantaged. These experiences will prepare students to incorporate the social determinants of health into practice.

In the longer term, integrate dental postdoctoral programs into the overall system of U.S. residency education. There are non-mutually exclu- 
sive strategies for providing postdoctoral students livable stipends. One way is to increase the number of postdoctoral students covered by federal GME support. Because dental schools cannot provide GME support directly, this would require closer integration with hospital residency programs or changes in federal regulations on the allocation of GME support. Another possibility is to establish patient-centered dental school clinics that generate adequate funds for resident stipends. The third strategy is to create partnerships between dental schools and large dental group practices to help fund the cost of CODAaccredited advanced dental education programs.

Welcome and facilitate basic oral health education for other health professionals. All medical and other health professions students need a basic understanding of oral diseases and treatments in order to recognize oral health conditions, assess oral health risks, participate in preventive activities on behalf of their patients, and refer patients to a dental home when needed. ${ }^{42}$ Oral health knowledge and skill can be conveyed through changes to educational curricula and continuing education programs.

\section{Insufficient Support for Research}

Growing numbers of the nation's 66 dental schools are not based in research universities, and research funds are highly concentrated in a relatively few schools. Thirteen dental schools account for almost $60 \%$ of total National Institutes of Health (NIH) research support to academic dental institutions, and $52 \%$ of dental schools average less than $\$ 500,000$ per year in NIH research dollars. ${ }^{46,50}$ Arguably, this amount is less than the minimum funding needed to sustain a viable research program.

Of considerable concern is the steep decline in NIH research applications from dental faculty members in the 30 to 41 years of age bracket. ${ }^{46,50}$ Few full-time dental clinical faculty members have the scientific training to compete successfully for research grants and contracts, whether from public research agencies or private foundations. Even faculty members who possess advanced scientific training often lack the institutional resources - a competitive salary, space, equipment, supplies, mentorship, access to postdoctoral students and research staff, and time to spend on research - that facilitate research careers.

As a result, most schools do not provide preand postdoctoral dental students with meaningful research experiences as a core part of their education, and few dental schools are on the cutting edge of the new scientific developments that will influence the future practice of dentistry. ${ }^{46,50}$ In part, this is because these schools are not closely integrated with other medical center and university research programsbut they could be. Key research topics that are ripe for collaboration include precision health care, health policy, global oral health, big data analytics, systems biology, genomics, transcriptomics, proteomics, metabolomics, and tissue engineering and regeneration.

The project's recommendations for this area are as follows:

Make research a core mission. Doing so is the first step toward ensuring that all dental schools develop active research programs.

Recruit research faculty members. Dental schools and allied dental programs should pursue policies to educate and recruit clinician-scientists who are able to compete for the extramural research funds needed to create new knowledge in their fields.

Increase support for early-stage researchers and students. The future of dental education depends on educating pre- and postdoctoral students to become the next generation of educators and scientists. The NIH has proposed grant support caps to wellfunded researchers to develop the next generation of scientists. ${ }^{46}$ Universities and dental schools can also establish more rigorous, mentored training programs to assist junior clinical faculty members in establishing sponsored, independent research programs.

Place increased emphasis on interdisciplinary and collaborative research. Clinical Translational Science Awards to universities promote interdisciplinary and collaborative clinical and translational research among all health science disciplines. Dental schools should take advantage of this NIH grant program as well as the emerging field of precision health to shift focus from disease management to disease prevention.

Address the structural barriers to developing strong research programs. Schools should allocate more resources to support faculty and student research and should foster an academic climate that places a high value on research activities. The $\mathrm{Na}-$ tional Institute of Dental and Craniofacial Research (NIDCR) should support a balanced portfolio that includes basic, clinical, behavioral, translational, and public health research, so that benchtop discoveries can be applied to patient care.

Strengthen CODA research standards for dental schools. CODA needs to develop accreditation metrics to strengthen and enforce its research standards. This regulatory activity will ensure that 
schools have strong research programs and that they provide students with meaningful exposure to different types of research and an understanding of research methods.

\section{Strategic Analysis of Challenges Facing Allied Dental Programs}

Despite their common focus on promoting oral health, the three established allied dental professions and the emerging field of dental therapy differ in fundamental ways. The educational pathways, work environments, and economic factors that characterize each of these professions produce different sets of challenges, which in turn merit different responses. As a result, the following analyses and recommendations are grouped by profession.

\section{Restorative Dental Technology}

With continuing improvements in oral health, the demand for dental prostheses is declining, especially for the upper income population, which primarily uses prosthetic services. ${ }^{28,51}$ Most missing teeth now occur in lower income populations that have limited financial access to these services. ${ }^{28} \mathrm{As}$ a result, the dental laboratory industry is being restructured, and the number of laboratories is declining. New and more efficient digital technologies, competition from overseas laboratories, and the consolidation of dental laboratories through acquisitions and mergers have further contributed to this decline. ${ }^{51}$

Few CODA-accredited restorative dental technology education programs remain, and CODA accreditation standards for these programs are largely based on traditional analog technologies. ${ }^{51}$ In 2015, there were 17 programs with 245 graduates. Further program reductions are likely, threatening the current structure of the restorative dental technology education system.

CODA-accredited restorative dental technology programs face major challenges. Many programs cannot afford the digital technology to prepare graduates for a changing industry. ${ }^{51}$ Many faculty members lack experience with new technology and the teaching experience or academic credentials to easily adapt to such a profound change in their roles. Even if experienced faculty and digital equipment were in place, the predominant two-year model of restorative dental technology education in community colleges is not long enough to teach both traditional and new restorative dental technologies. Currently, close to $40 \%$ of laboratory technicians receive limited on-the-job training and compete successfully for positions with formally educated restorative dental technologists.

The project's recommendations are as follows:

Require four years of education for all CODA-accredited restorative dental technology programs. CODA should require four years of education, leading to a baccalaureate degree with a strong concentration in digital CAD-CAM technologies for all restorative dental technology programs. Some programs are already offering four years of education. As the number of dental technology education programs and students continues to decline, consideration needs to be given to integrating this field with another health profession.

Move clinical education to digitally equipped, community-based care settings. Most dental technology programs will not be able to afford the requisite digital equipment. Similar to the education of physicians, nurses, and pharmacists, the applied side of the program needs to take place in commercial delivery systems where students have access to the digital equipment they will be expected to use.

\section{Dental Assisting}

A large but unknown percentage of active dental assistants are trained on-the-job, and most of those who receive formal training attend programs not accredited by CODA. ${ }^{52}$ There are also major differences among states in the standards used to certify dental assistants, to define their roles, and to delineate the specific procedures they can legally perform. No studies have been done to assess the performance of graduates from CODA-accredited versus nonaccredited programs.

The variation in training and state standards makes it difficult to develop national standards and performance measures for dental assisting education programs. ${ }^{52}$ This is especially concerning because more states are approving the use of expanded function dental assistants. CODA-accredited dental assisting programs are required to prepare students to provide these expanded functions, but states vary in their requirements for other dental assisting education programs and certification.

A lack of faculty diversity and, in nonaccredited programs, limited preparation for the faculty role also challenge dental assisting programs. ${ }^{52}$ Currently, there are limited opportunities for dental assisting career laddering, either academically or professionally. 
The project's recommendations are as follows:

Ensure that CODA-accredited dental assisting programs impart knowledge and skills that cannot be obtained on-the-job. The Dental Assisting National Board (DANB) and CODA's Dental Assisting Review Committee need to continue their efforts to establish a common core set of knowledge and skills that will foster greater uniformity among CODA-accredited programs. These programs also need to hire more diverse faculties and better prepare them for full-time academic careers. CODA accreditation should signal that programs graduate students with a high level of skill, including the ability to perform expanded functions (regardless of whether states currently allow dental assistants to perform such functions).

Prepare graduates for tomorrow's work environments. Dental assisting education programs need to prepare graduates to work with other health professionals in large group dental practices and community-based delivery systems.

Create opportunities for relevant credit transfers. Without the ability to transfer dental assisting course credits or test out of prerequisite courses for other allied dental education programs, dental assisting program graduates have little incentive to further their formal education and expand their skills.

Work to create more standardization among state practice acts. Doing so will help to reduce variation in dental assisting training and smooth the way for preparing more expanded function dental assistants.

\section{Dental Hygiene}

Not all 336 dental hygiene programs are filled to capacity, and some states are producing more dental hygienists than they can fully employ ${ }_{.}^{53}$ Some non-dental settings already employ dental hygienists; although these seem likely to become a major source of new dental hygiene employment opportunities, few dental hygiene programs currently prepare students to work in those environments. As students, most dental hygienists do not receive any experience working in non-dental settings with medical personnel. In such settings, dental hygienists could provide both dental care and some basic medical screening and preventive services. The traditional dental hygiene curriculum implicitly assumes that most graduates will be employed in small dental practices. Consequently, programs are not preparing graduates to adapt to the changes taking place in the dental and medical care systems.
A review of U.S. dental hygiene programs revealed important gaps in the curricula, failing to address connections between oral and overall health; the larger health care delivery system; population health, including social determinants of health; risk assessment and prevention; digital technologies; intra- and interprofessional education; cultural competence; community-based clinical experiences; and the care of vulnerable populations. ${ }^{53}$ Most dental hygiene programs are also hampered by a lack of diversity in the faculty ranks and an insufficient number of faculty members who are prepared for full-time academic careers in colleges and universities. In addition, the scope of dental hygiene practice varies considerably among states, often contributing to underuse of welleducated oral health professionals.

Dental hygienists are not adequately represented on CODA and the state dental boards that accredit and regulate dental hygiene education and practice..$^{53} \mathrm{As}$ a result, the dental hygiene profession itself has limited ability to mandate actions to address these challenges.

The project's recommendations are as follows:

Transition to the baccalaureate degree for entry into practice. Because of the need to fulfill prerequisites, most graduates of two-year associate degree programs already spend three years obtaining their degree..$^{53}$ Although CODA accreditation standards do not differentiate between associate and baccalaureate degree programs, graduates from associate degree programs have limited career opportunities. Developing articulation agreements between existing associate degree programs and baccalaureate degreecompletion programs will facilitate the transition to a four-year degree for entry into practice.

Prepare students for emerging practice environments. Dental hygiene curricula should be strengthened to address the areas of weakness noted above. Additions should include some basic nursing assessment skills to prepare dental hygienists to work with medical and nursing personnel in non-dental settings such as schools, long-term care facilities, large group medical practices, and hospitals. Interprofessional education is another critical component of dental hygiene curricula that needs additional emphasis.

Develop educational pathways for dual dental hygiene-dental therapy degrees. As part of a baccalaureate program, tracks should be developed to give interested dental hygiene students the option of obtaining the knowledge and skills of dental therapists. Advanced, accelerated, and dual-degree programs available to other health professionals can serve as models. 
Develop additional educational pathways for dental hygienists interested in academics, research, industry, and public health careers. Baccalaureate degrees position dental hygienists for graduate education and open up opportunities to assume roles in primary care and interprofessional delivery settings. There are currently few graduate degree opportunities that position dental hygienists to advance on a career ladder.

Invest in developing diverse faculty for fulltime academic careers. Dental hygiene programs should recruit a more diverse group of educators who are prepared for full-time academic careers in university-based programs. The faculty also should include researchers who can contribute to the development of new knowledge.

Increase dental hygienists' role in regulating dental hygiene education. The dental hygiene profession itself needs to play a greater role in the regulatory organizations that influence dental hygiene education and practice. This involvement will help dental hygienists facilitate broader scopes of practice with requisite educational programs. In some states, the dental hygiene profession has its own board or is governed by an institution other than the state's dental board. This alternative oversight would allow the profession more self-regulation and the potential for scopes of practice that are both broader and more uniform across states.

\section{Dental Therapy}

In the U.S., dental therapy is at an early stage of development. Currently, dental therapy education programs are operating in Minnesota and in Alaska through the Alaska Native Tribal Health Consortium. ${ }^{54}$ Two dental therapy education programs are in the planning stages in Vermont and Maine, and at least ten more states are considering legislation to permit dental therapists.

The influence of dental therapists over the next 25 years is hard to predict, but early descriptive studies of dental therapists in Minnesota and in Alaskan native communities have been positive, indicating that dental therapists increase access to dental care and are accepted by patients. ${ }^{54}$ CODA standards for the accreditation of dental therapy programs were introduced in 2016 and are a major step forward in the effort to formalize dental therapy education, but it may take considerable time before the role of dental therapists fully evolves and U.S. educational programs provide options for the best ways to prepare these providers.
The project's recommendations are as follows:

Increase the availability of dental therapy education. States should continue the process of passing legislation to permit the practice of dental therapy, and new programs should continue to develop based on experiences in Alaska and Minnesota and other countries. Programs should adhere to the CODA standards for dental therapy programs.

Respect local variation and flexibility in dental therapy education models as the field develops. No long-term decisions should be made on the education of dental therapists. These providers may develop different roles in different organizations and clinical settings. Dental therapists may provide some general and some specialty dental services, working under a range of levels of supervision from both dental and medical providers. Time is needed to see how this new profession develops in various regions and delivery settings.

\section{Discussion}

The findings of this investigation and the vision of dentistry it puts forth for 2040 are similar to those presented in the IOM report Dental Education at the Crossroads. ${ }^{2}$ This comes as no surprise, given that the trends documented in this project were already evident in 1995. It is concerning, however, that the IOM's 1995 report has had only a modest effect on dental education during the intervening years.

Will this report have more traction? At the time of the IOM study, dentist incomes were increasing $5 \%$ to $10 \%$ a year, and the demand for dentists was growing. ${ }^{37}$ Today, the per capita demand for dental care is not keeping pace with the rapid growth in the number of dental graduates, and the annual increase in dentist incomes has also slowed. Most dental students graduate with substantial debt, which will likely lead to a decline in the number and quality of applicants. This eventuality poses a serious threat to dental schools, which are economically dependent on large classes of students who pay high tuition and fees. Confronted with these challenges, dental schools may take a more serious look at new, more sustainable models for educating future dentists.

\section{Moving Toward Patient-Centered Clinics in Dental Education}

Central to our vision for dental education in 2040 is the shift from student- to patient-centered clinics, both on- and off-campus. Although this vision 
is achievable, the difficulties of transitioning to a patient-centered model of dental care should not be underestimated. The student-centered model has a long history and is sustained by a strong culture and a clinical faculty that has known no other system. Uprooting the old model will take time and require strong leadership from school, medical center, and university administrators.

At many schools, increased federal and state support for oral health care will also be needed to fully implement this shift. Recognizing dental schools as an important component of the safety net system and providing them with public subsidies similar to those provided to FQHCs would ease this transition, but garnering this support is not guaranteed. To effect such a change will require the active commitment of organized dentistry and strong advocacy efforts by the oral health community. It is encouraging to note that, even without these supports, many schools are already transitioning substantial amounts of predoctoral clinical education to community-based, patient-centered clinics or modifying the way care is delivered in dental school-based clinics.

The shift to patient-centered care delivery is only one of several considerable challenges identified by the "Advancing Dental Education in the 21 st Century" project. Others include health system consolidation, the emergence of large group dental practices, and capitated and other forms of payment that put providers at risk. Health professions educators have widely embraced one key strategy for meeting the demands of this evolving care environment: interprofessional education experiences that prepare students to work in collaborative teams. Yet, despite some philanthropic and technical support, many health professions students still graduate underprepared for collaborative care environments.

\section{Increasing Emphasis on Research in Dental Education}

In 1926, William Gies envisioned an "enlarged dentistry, [in which] its practitioners would be trained to give the service not only of dental surgeons and dental engineers as at present, but of oral sanitarians and oral physicians as well." " He foresaw that dentists would go beyond a "restricted view of their responsibility [and] recognize and note the possible outstanding symptoms of systemic disease." He further stated that "dentistry should no longer be ignored in medical schools, and its main health-service features should be given suitable attention in the training of general practitioners of medicine."
Gies was correct in thinking that research findings could bring the two fields back together. A background article for our project clearly documents why the field should not focus on the oral cavity alone, but should take responsibility for monitoring oral and systemic conditions, especially those related to the oral cavity. ${ }^{46}$ Likewise, medical education should educate its practitioners to appreciate the value of oral health care, providing at least enough understanding of dentistry as provided to medical students about other specialties such as ophthalmology and dermatology. ${ }^{42}$

It has taken 92 years since the publication of the Gies report for many to grasp the wisdom of his vision, and we are only at the beginning of fully implementing the reciprocal relationship he proposed between the fields of medicine and dentistry. One facet of his vision remains especially resonant today: that research is a fundamental responsibility of all medical fields in order to both advance and improve the health of the public.

Background articles published in Phase 1 of this project support the notion that dental schools must find a balance between educating students in science and clinical skills. ${ }^{22,23,25,46}$ Research is but one component of a scholarly environment. Schools should strive for graduates who are intellectually curious and literate and worthy of the trust that the public places in professional individuals. We believe that the capacity exists for dental education to achieve this goal. We are optimistic that, over the next 25 years, a new generation of faculty members will drive the changes recommended in this report.

\section{Addressing New Needs in Allied Dental Education}

The four allied dental professions face equally serious challenges. Technological change has placed the restorative dental technology profession at a critical turning point: the profession must embrace the digital age or become obsolete. ${ }^{53}$ Expansion of the dental assisting role by a growing number of states enriches career prospects, but the small number of CODA-accredited educational programs limits dental assistants' advancement. Dental hygiene is poised for even greater professional growth, with rising opportunities for practice in a wide range of settings outside the dental office and the potential to acquire new and relevant competencies such as the use of salivary diagnostics, interprofessional collaboration, and select procedural skills. However, restrictive accreditation 
standards, a two-tiered educational model (associate and baccalaureate), and curricular gaps may stymie this forward progress. Finally, more and more states and tribal authorities are welcoming dental therapists as part of their provider mix, but programs to educate these providers are few and far between.

As a group, the allied dental professions are limited by the extensive variation in how states certify practitioners, regulate their scopes of practice, determine supervision requirements, and designate the environments in which they can practice. $.^{53} \mathrm{Re}-$ strictive accreditation standards also deter progress. These challenges make it difficult to improve educational programs to ensure that all graduates will be prepared to a uniformly high level of competence for practice in 2040. Leaders in dental and allied dental education and practice must take a stand to ensure that allied dental professionals become an integral part of team-based, interprofessional primary care that is delivered in a variety of medical, dental, and other health care settings.

\section{The Change Process}

This report strives to give educational programs, university leaders, and others a better understanding of the current and future challenges facing dental education. We have presented options for addressing these challenges, but the report is not prescriptive. There is already a rich body of literature on the major steps that need to be taken to implement some of the recommendations. More important, the change process at any one school or program has to account for local historical, political, educational, and economic considerations. Changes in government policies require constant monitoring as well because they can greatly affect dental education and research.

Charting a new course for dental education will take time and be difficult. Nevertheless, it is imperative that the dental education community embrace change and that each institution finds a path forward. Resisting change can also be disruptive and even damaging to institutions that do not adapt.

\section{Limitations}

Strategic planning reports have three inherent limitations. First, planners typically lack complete and sufficiently accurate baseline data to make precise long-range predictions. Second, analyzing even the best data to predict what is likely to happen is inherently challenging. Third, some future events simply cannot be predicted. As a result, no single re- port can possibly cover all of the trends that will affect dental education in a rapidly changing environment.

Despite these limitations, this project engaged 70 nationally recognized educators to assess the current state of dental care and dental education. Many knowledgeable individuals then reviewed the contents of this report, and although there was not consensus on every recommendation, each was supported by a majority of reviewers. The resulting recommendations are not cast in stone. As with any good strategic planning process, they should be reviewed and amended every few years. These recommendations, imperfect though they may be, represent a serious effort to address the complex challenges facing dental education and to offer a clear vision that can guide the dental education community in addressing the challenges it faces.

\section{Conclusion: Guiding Principles}

The strategic analyses and recommendations from this project suggest several principles to guide the future of predoctoral, allied, and advanced dental education. Most of these principles are well established in the dental professions, but they take on new importance given changes in society and the delivery system, improvements in oral health, advances in science and technology, and the complexity of today's evolving environment. These principles are as follows:

Dental schools should be models of patientcentered, collaborative care, offering the most advanced and efficient, evidence-based oral health care available. All students should be educated in this type of clinical environment, working in intra- and interprofessional teams that consider the oral and general health of all patients.

Dental education should be integrated wherever possible with the education of other health professions students. Oral health professionals should be able to screen for and help monitor some chronic medical conditions, and physicians and nurses should be able to screen for and monitor some oral diseases. The dental workforce, physicians, and nurses are ethically responsible for caring for the whole patient — not just their practice domains.

Academic dental institutions should provide a supportive scholarly environment for educating the next generation of professionals, and they should 
have the same research mission as their parent research universities. As an integral part of the higher education community, these institutions should contribute their special expertise to advance the welfare of society.

Dental education must be provided by an enlightened faculty able to integrate foundational scientific knowledge and the special skills needed to provide oral health services into a cohesive whole throughout the pre- and postdoctoral education period. As part of a respected and learned profession, dental schools should always strive for excellence, helping to advance their professions and to serve their local communities.

Almost 100 years ago, William Gies argued that dentistry (then an apprentice system) should be considered a specialty of medicine, but acknowledged that the full integration of medical and dental education was not feasible. ${ }^{1}$ Practical barriers to implementing Gies's vision still exist, but with dental education now well established in academia, the time has come to heed his call for closer integration of the two fields. Today's educational and health care environments present unprecedented opportunities for collaborations that can improve patient care, and pioneering institutions have already begun to implement Gies's vision for bringing together dentistry and medicine. All dental, allied dental, and advanced dental education programs should strive for increased collaboration with medicine and other health professions if dentistry is to remain a learned profession and the oral health professions are to thrive in a changing research and practice environment.

\section{Acknowledgments}

The authors are grateful for the time and effort of the 70 authors (listed in Table 1) who prepared background articles for Phase 1 of this project. We also appreciate the reviews and comments from the 26 outside reviewers of this Phase 2 report, and we thank the other members of the Planning Committee for the National Conference: Cecile Feldman, Chair; Teresa Dolan, Christopher Fox, Michael Reddy, Leo Rouse, and Anthony Zeibert. This committee, along with Janice Gibbs-Reed, Executive Director of Rutgers School of Dental Medicine Office of Continuing Education, and her staff, provided expert assistance for the National Conference. The conference was enriched through the leaders of the five workshops: Lisa Tedesco, Marko Vujicic, Michael Reddy, Pamela Zarkowski, Colleen Brickle, and Kenneth Kalkwarf.
We thank them for their efforts on the project. We appreciate the editorial assistance of Nicole Fauteux who assisted us through the difficult process of making the initial manuscript more "reader-friendly." The multiple funders of this project made it possible for us to take on the project and conduct it in a thorough fashion. For their support, we thank the American Dental Education Association, American Association for Dental Research, Bien-Air Company, ColgatePalmolive, Delta Dental Plans of Michigan, Delta Dental Plans of Wisconsin, Dentsply Sirona, Henry Schein Company, Macy Foundation, and Pew Foundation. We are also grateful to Colgate-Palmolive and Dentsply Sirona for their co-sponsorship of the conference.

\section{Disclosure}

The authors reported no conflicts of interest in connection with the writing of this report.

\section{Editor's Disclosure}

This report is published as part of a special project that was conducted independently of the American Dental Education Association (ADEA). The manuscript, authored by the project's leadership team, was reviewed by outside reviewers selected by the project directors, and the final manuscript was then assessed for general content and edited by the journal's editorial staff. Any opinions expressed are those of the authors and do not necessarily represent the Journal of Dental Education or ADEA.

\section{REFERENCES}

1. Gies WJ. Dental education in the United States and Canada: a report to the Carnegie Foundation for the Advancement of Teaching. New York: Carnegie Foundation, 1926.

2. Field MJ, ed. Dental education at the crossroads: challenges and change. An Institute of Medicine report. Washington, DC: National Academies Press, 1995.

3. ADEA Commission on Change and Innovation in Dental Education. Beyond the crossroads: change and innovation in dental education. Washington, DC: American Dental Education Association, 2010. At: www.adea.org/adeacci/ Publications/Pages/default.aspx. Accessed 19 Feb. 2017.

4. Hendricson WD. The ADEA CCI series of articles: perspectives and reflections in dental education. J Dent Educ 2009;73(2):160-5.

5. Palatta A, Cook BJ, Anderson EL, Valachovic RW. 20 years beyond the crossroads: the path to interprofessional education at U.S. dental schools. J Dent Educ 2015;79(8):982-96.

6. American Dental Education Association. Dental school applicants and first-time enrollees, 1980-2017. 2018. At: www.adea.org/data/students/. Accessed 23 Apr. 2018. 
7. Formicola AJ. Current state of dental education: executive summary. J Dent Educ 2017;81(8):1008-14.

8. Bailit HL, McGowan TL. Senior dental students' impact on dental school clinic revenues: the effect of community-based dental education. J Dent Educ 2011;75(10 Suppl):S8-13.

9. Bailit HL. Are dental schools part of the safety net? J Dent Educ 2017;81(8 Suppl):eS88-96.

10. Nasseh K, Vujicic M. Dental care utilization steady among working-age adults and children, up slightly among the elderly. ADA Health Policy Institute, Research Brief, 2016. At: www.ada.org/-/media/ADA/Science $\% 20$ and $\% 20$ Research?HPI/Files/HPIBrief. Accessed 4 March 2017.

11. Formicola AJ. Ten-year student trends in U.S. dental schools, 2004-05 to 2014-15. J Dent Educ 2017;81(8 Suppl):eS33-40.

12. Licari FW, Evans CA. Clinical and community-based education in U.S. dental schools. J Dent Educ 2017;81(8 Suppl):eS81-7.

13. Reinhardt JW. Current status of operations and management of dental school clinics. J Dent Educ 2017;81(8 Suppl):eS50-4.

14. Herzog CR, Berzins DW, DenBesten P, et al. Oral sciences $\mathrm{PhD}$ program enrollment, graduates, and placement: 19942016. J Dent Res 2018;97(5):483-91.

15. Formicola AJ, D’Abreu K, Tedesco LA. Underrepresented minority dental student recruitment and enrollment programs: an overview from the dental pipeline program. J Dent Educ 2010;74(10 Suppl):S67-73.

16. Anderson RM, Carreon DC, Davidson PL, et al. Who will serve? Assessing recruitment of underrepresented minority and low-income dental students to increase access to care. J Dent Educ 2010;74(6):579-92.

17. Mofidi M, Konrad TR, Porterfield DS, et al. Provision of care to the underserved by National Health Corps alumni dentists. J Public Health Dent 2002;62(2):102-8.

18. Logan HL, Guo Y, Dodd VJ, et al. Demographic and practice characteristics of Medicaid participating dentists. J Public Health Dent 2014;74(2):139-46.

19. Mertz EA, Wides CD, Kettek AM, et al. Underrepresented minority dentists: quantifying their numbers and characterizing the communities they serve. Health Aff 2016;35(12):2190-9.

20. Commission on Dental Accreditation. Accreditation standards for dental education programs. Chicago: American Dental Association, 2016.

21. Formicola AJ, Bailit HL. Community-based dental education: history, current status, and future. J Dent Educ 2012;76(1):98-106.

22. Centore L. Trends in behavioral sciences education in dental schools, 1926 to 2016. J Dent Educ 2017;81(8 Suppl):eS66-73.

23. Lantz MS, Shuler CF. Trends in basic science education in dental schools, 1999-2016. J Dent Educ 2017;81(8 Suppl):eS55-65.

24. Hamil LM. Looking back to move ahead: interprofessional education in dental education. J Dent Educ 2017;81(8 Suppl):eS74-80.

25. Kassebaum DK, Tedesco LA. The $21^{\text {st }}$-century dental curriculum: a framework for understanding current models. J Dent Educ 2017;81(8 Suppl):eS13-21.
26. Weintraub JA. What should oral health professionals know in 2040: executive summary. J Dent Educ 2017;81(8):1024-32.

27. Formicola AJ. Trends in dental faculty of U.S. dental schools, 2003-04 to 2013-14. J Dent Educ 2017;81(8 Suppl):eS33-40.

28. Rozier RG, White BA, Slade GD. Trends in oral diseases in the U.S. population. J Dent Educ 2017;81(8 Suppl):eS97-109.

29. Manski RJ, Meyerhoefer CD. Projecting the demand for dental care in 2040. J Dent Educ 2017;81(8 Suppl):eS133-45.

30. Eklund SA. The impact of improved oral health on the utilization of dental services. J Dent Educ 2017;81(8 Suppl):eS110-9.

31. Eklund SA, Bailit HL. Estimating the number of dentists needed in 2040. J Dent Educ 2017;81 (8 Suppl):eS146-52.

32. Personal communication with Dr. Fred Eichmiller, Delta Dental Plan of Wisconsin, 2016. In this privately insured population, dental implants accounted for $2 \%$ of total practice revenues.

33. Munson B, Vujicic M. Supply of dentists in the United States is likely to grow. ADA Health Policy Institute, Research Brief, Oct. 2014. At: www.ada.org/ /media/ADA/Science $\% 20$ and\%20Research/HPI/Files/HPIBrief_1014_1.ashx. Accessed 23 June 2016.

34. Munson B, Vujicic M. Number of practicing dentists per capita in the United States will grow steadily. ADA Health Policy Institute, Research Brief, June 2016 (revised). At: www.ada.org/ /media/ADA/Science $\% 20$ and $\% 20$ Research/HPI/Files/HPIBrief 0616 1.pdf?la=en. Accessed 23 June 2016.

35. Munson B, Vujicic M. Dentist earnings were stable in 2015. ADA Health Policy Institute, Research Brief, Dec. 2016. At: www.ada.org/ /media/ADA/Science $\% 20$ and\%20Research/HPI/Files/HPIBrief 1216 1.pdf?la=en. Accessed 23 June 2016.

36. Gesko DS, Bailit HL. Dental group practice and the need for dentists. J Dent Educ 2017;81(8 Suppl):eS120-5.

37. Bailit HL. How many dentists are needed in 2040: executive summary. J Dent Educ 2017;81(8):1015-23.

38. Milgrom PM, Horst JA. The effect of new oral care technologies on the need for dentists in 2040. J Dent Educ 2017;81(8 Suppl):eS126-32.

39. Fontana M, Gonzalez-Cabezas C, de Peralta T, Johnsen DC. Dental education required for the changing health care environment. J Dent Educ 2017;81(8 Suppl):eS153-61.

40. Brickle CM, Self KD. Dental therapists as new oral health practitioners: increasing access for underserved populations. J Dent Educ 2017;81(9 Suppl):eS65-72.

41. Bailit H, D'Adamo J. State case studies: improving access to dental care for the underserved. J Public Health Dent 2012;72(3):221-34.

42. Silk H. The future of oral health care provided by physicians and allied professionals. J Dent Educ 2017;81(8 Suppl):eS171-9.

43. Nasseh K, Vujicic M. The relationship between education debt and career choices in professional programs: the case of dentistry. J Am Dent Assoc 2017;148(11):825-33.

44. Bailit HL. The oral health care delivery system in 2040: executive summary. J Dent Educ 2017;81(9):1124-9. 
45. Bailit HL, Plunkett M, Schwarz E. The Oregon dental market: a case study. J Am Coll Dent 2016;83(2):14-23.

46. Polverini PJ, Krebsbach PH. Research and discovery science and the future of dental education and practice. $\mathrm{J}$ Dent Educ 2017;81(9 Suppl):eS97-107.

47. Assael L. Current status of postdoctoral and graduate programs in dentistry. J Dent Educ 2017;81(8 Suppl):eS41-9.

48. Thierer TE, Meyerowitz C. Trends in general and specialty advanced dental education and practice. J Dent Educ 2017;81(8 Suppl):eS33-40.

49. Glick M, Greenberg BL. The role of oral health care professionals in providing medical services. J Dent Educ 2017;81(8 Suppl):eS180-5.
50. Ferland CL, O'Hayre M, Knosp WM. The NIH's funding to US dental institutions from 2005 to 2014. J Dent Res 2017;96(1):10-7.

51. Bobich AM, Mitchell BL. Transforming dental technology education: skills, knowledge, and curricular reform. J Dent Educ 2017;81(9 Suppl):eS59-64.

52. Kracher C, Breen C, McMahon K, et al. The evolution of the dental assisting profession. J Dent Educ 2017;81(9 Suppl):eS30-7.

53. Fried JL. The allied dental health professions: executive summary. J Dent Educ 2017;81(9):1130-6.

54. Brickle CM, Self KD. Dental therapists as new oral health practitioners: increasing access for underserved populations. J Dent Educ 2017;81(9 Suppl):eS65-72. 


\section{APPENDIX 1}

\section{Workshop Reports from the National Conference}

On June 27-28, 2018, a National Conference was held at Rutgers School of Dental Medicine to discuss the recommendations from the Phase 2 report. Approximately 100 individuals attended the conference. Five workshops were held, covering the 20 recommendations for dental education and 14 recommendations for allied dental education. Participants selected one of the five workshops to attend and received the draft Phase 2 report prior to the meeting. Workshop leaders who were not authors of the report conducted the workshops. Each workshop was staffed with two recorders, and Phase 1 article authors were available as resources. The workshop leaders summarized the discussions from their groups in a plenary session. After the conference, written workshop reports were prepared and were reviewed by the workshop leaders and participants. Following are the final summaries of discussions from each workshop and the plenary session.

\section{Current and Future State of Dental Education}

Lisa Tedesco, PhD, Dean of the James T. Laney School of Graduate Studies and Vice Provost for Academic Affairs, Graduate Studies, Emory University, led this workshop for participants to discuss the five recommendations made in the "Outdated Financial and Educational Models" area. Those recommendations were to 1) move from a student-centered to a patient-centered model of care to transform the economics of clinical education; 2) increase federal and state subsidies for safety net care; 3) strengthen and integrate teaching of the clinical, biomedical, population health, and behavioral sciences; 4) invest in developing a well-qualified and diverse faculty for full-time academic careers and recruit a diverse student body; and 5) increase diversity of thought in the accreditation process.

Overall, the discussions on these recommendations were engaged, energetic, and broad-ranging. There was no disagreement with the first three recommendations as important directions for the future. However, it was pointed out that it was important to define under whose purview the recommendations fall if they are to promote action. For example, increasing federal and state subsidies for safety net care provided in dental school clinics would require government action, whereas moving from student-centered to patient-centered dental clinics was directly under the control of the schools. It was suggested that schools should concentrate on where they can change and innovate and to understand that schools must build relationships to advocate and influence the areas beyond their capacity for action. Further, it was pointed out that the recommendations may be more appropriate for some schools than for others.

There was some tension over the recommended shift from student-centered to patient-centered clinics since it would involve replacing the predominant model in place. Change would require a cultural shift in the clinical faculty members' role to include more active involvement in patient care than presently structured. It was pointed out that some schools (two or more) are using patient-centered community-based sites for major portions of their students' clinical education. However, data are not yet available on whether this approach reduces the cost of clinical education, one of the intended benefits of shifting to patient-centered clinics as well as improving education. It was clear from the discussion that (as the report recommends) improving schools' ability to access new reimbursement mechanisms such as those provided to FQHCs is essential to revenue that could then be used to reduce the heavy burden on student tuition. As this work goes forward, it was suggested that the term "personcentered" rather than "patient-centered" be used to bring the concept into contemporary language that aligns with research evidence on the social determinants of health.

There was lively discussion about dental school curricula that went beyond the recommendation to integrate various components. Examples included the following: overhauling the current model of four years of education that produces a graduate ready for independent practice to three years of education and a required one year of residency, funded by GME, similar to the model medical education uses to graduate resident-ready students; increasing curriculum connections between medical and dental schools further, as Harvard and the University of Connecticut are exploring; and restructuring from educating for entry into practice for a solo provider framework to working in teams as group dental and interprofessional practices continue to grow. There was some discussion 
on the lock-step curriculum and its tension with competency-based education. Questions raised were: What would education look like if students advanced at their own speed? And how could movement to advancing students based on skill acquisition improve patient care and clinical finances?

There was strong concurrence and urgent recognition for the fourth recommendation to increase the diversity of the faculty and student body. Efforts were endorsed to redouble actions by methods already well known and to implement proven lessons learned from the Pipeline, Profession, and Practice: Community-Based Dental Education program such as whole-file review for admissions, establishing relationships with community and other colleges to establish pathway programs to dentistry, summer pipeline programs to prepare underrepresented minority students for dental school, and programs that train faculty with skills for mentoring that advance diversity and inclusion in the student body and among faculty colleagues.

The workshop participants agreed with the fifth recommendation that CODA has an important role in enabling innovation that shifts educational direction. A more flexible understanding of the accreditation process recommendations, coming from site visit committees, can serve as a positive way of assisting schools for change. Rather than considering recommendations as negatives, understanding how we might move away from institutional lack of responsiveness to CODA standards toward establishing new educational norms is needed. Further, adding greater diversity to site visit team members as part of the peer review process is needed to assist the change and innovation process and should reflect inclusion of other than dental health professionals.

Attendees at this workshop: Lisa Tedesco, Workshop Leader; Mert Asku, Gregory Chadwick, Joseph Crowley, Cecile Feldman, Allan Formicola, Janet Guthmiller, Karen Hart, Frank Licari, Monty MacNeil, Richard Manski, Keith Mays, Dwight McLeod, Michael Pagan, Barbara Shearer, Clark Stanford, Sherin Tooks, John Williams. Recorders: Kim Fenesy, Shawn Kelly.

\section{What Oral Health Professionals Need to Know and the Oral Health Delivery System in 2040}

Dr. Michael Reddy, Dean of the University of California, San Francisco School of Dentistry, led this workshop. Five recommendations in the "Shifting Practice Environment" area and one recommendation in the "Outdated Financial and Educational Models" area were discussed.

Strengthen and integrate teaching of the clinical, biomedical, population health, and behavioral sciences. There was widespread agreement on the need to contemporize both curriculum content and pedagogy. Contemporary teaching methods need to be employed to facilitate as much active learning as possible. The lecture format needs to be minimized since it is less effective then other modes of active, experiential learning. In contrast to lectures, guiding students in the application of knowledge is much more likely to be effective. It was noted that the integration of clinical, biomedical, and behavioral sciences has been a CODA standard for many years, but there are still many opportunities for improvement. Content in each of these areas is well covered in our curricula, yet it was felt that curriculum content is still siloed by course or topic so the need to continue to stress integration still exists. In particular, behavioral sciences (including population health), public health sciences (including social determinants of health), and patient management education need to be strengthened and integration fostered, including integration of these topics into the preclinical aspects of dental education.

The term "behavioral sciences" was unclear to some, and it was suggested that the term "social sciences" be used instead as population health, public health, social determinants of disease, etc. need to be included. It was also emphasized that dental students need to learn to work with social workers and other patient navigators, and our patient care settings need to be more patient-focused. In addition, some felt that the term "biomedical" usually refers to basic sciences. It was felt that clinical "medicine" should be added as another area that should be integrated. Some also felt that the term "teaching" should be changed to "learning," arguing that it is not what we teach that is important, but, rather, what is learned.

If this recommendation were fully implemented, it could have a very significant impact on our students and their patient care. Faculty and staff development and collaboration across disciplines and health professions would need to occur, and team teaching encouraged. If faculty members do not integrate basic, clinical, and behavioral sciences in their didactic and clinical courses, neither will the students. As active learning can take more time than lectures, efficiencies (time and dollars) will need to be found, and decisions made about what curriculum content to omit or pare down. 
Move more clinical education to patient-centered delivery settings. While all schools have comprehensive care delivery models (a current CODA requirement), few are truly patient-centered in that patients are often viewed as teaching material, and delivery of care is being provided in inefficient ways. Examples of schools' being non-patient-centered are when they determine that certain patients are "non-clinical," "too complicated," or "not a teaching case." These comments refer to patients' needs being beyond the capabilities of a dental student, and therefore the patient is not able to get care at the school. As in workshop 1, it was recommended that the term "patient-centered" be changed to "person-centered." Currently, the curriculum is mostly student-centered.

Participants discussed that there should be more of a shift to a variety of community settings where people are located, such as schools, nursing homes, and FQHCs, and offer opportunities to work in intra- and interprofessional teams. Changes in student assessments may need to reflect the team rather than the individual. In such settings, each student could have very different experiences due to variations among settings. Thus, schools may need to balance students' clinical experiences.

From a financial perspective, at some FQHCs, procedures can be reimbursed at a higher rate than at a dental school if the student is providing care under the supervising dentist's license. In some schools, dental students pair up and gain experience in being assistants, which can aid productivity. This process is less expensive for the facility than hiring dental assistants, but dental students often are without the appropriate training for this role. A concern was raised about a possible unintended consequence of students' being considered low cost labor for the community.

It was noted that, within different delivery systems, there may be variation in treatment recommendations, including those related to costs. Thus, time for reflection and discussion is required after these rotations to enable students to consider the value of services provided compared to alternative treatment plans.

Benefits noted of implementing this recommendation included exposing students to different kinds of delivery settings and providing students with real-life delivery system experiences. In the future, these systems may include more teledentisty or aspects of virtual care and self-care and focus more on prevention and precision medicine/ dentistry. Many felt that if this recommendation was not implemented, dental education would be in jeopardy because of the economic burden placed on dental schools due to their current expensive clinical enterprises.

The question was also raised about the current four-year curriculum for a DMD or DDS degree. If dental education has become competency-based, why can't a student graduate either early or late depending on his or her development?

Prepare students to manage the care of children and treat patients with complex dental and health care needs. Currently, dental school patients are typically healthy, ambulatory patients, but changes in population demographics indicate that our graduates need to be able to care for people across the lifespan. Preparing students to manage patients of all ages and with complex needs may require creativity, time, funding, and collaboration with community hospitals with available operating rooms or facilities with dental operatory wheelchair accessibility. Complex patients - the type who are often rejected as too difficult for students to treat in school clinics - are the patients who prepare students to meet this goal. It was generally agreed that students need this type of experience; however, it was noted that "manage" does not mean performing all care, as observation or referral to other providers may be appropriate. It was suggested to change the wording to "Prepare students to manage persons of all ages with complex dental, behavioral, and health care needs." In addition, it was suggested to incorporate "cultural competence" or "cultural humility" into this recommendation as dentists would be able to better recognize and respond to their increasingly diverse patient population's needs.

Participants discussed that there could be major market disruptors of traditional dental practices in the future such as delegating responsibility for prevention/hygiene services by allied dental personnel outside of dental offices or shifting to a medical model for emergency and urgent care. The dental delivery systems including the dental school clinics need flexibility to accommodate limited care options when desired by the patient.

Increase the integration of dental and medical education and practice (interprofessional education). The need for increased integration of medical and dental education was discussed, and it was recommended that the concept be expanded to include other aspects of health care. The prospect of a well-designed wellness program including health risk appraisal, nutritional counseling, and health education was supported. Dental staff should be involved with programs customized to meet the needs of the patient. Having an ability to measure return on investment for provision of traditionally medical diagnostic and preventive services in the dental environment will be helpful. It was suggested to consider adding wording to the recommendation to reflect "interprofessional collaborative practice." 
A word of caution was expressed as interprofessional models created in dental schools may not translate outside of the school environment, where professional turf and boundary issues exist and dentistry is siloed from other health professions. Good interprofessional models are needed, and community health centers where multiple professionals are already located may serve this purpose well. It was thought, however, that delivery systems will change over time and with these changes will come the need for faculty and dental institutions to change. Many felt that reimbursement models will continue to affect the likelihood of oral health services being provided in a medical setting and medical screening services in a dental setting. These activities are currently more likely to occur in accountable care organizations or places where services are bundled or not reimbursed per procedure or where reimbursement for value-based care has been enacted.

Currently, academic dental practices (in dental schools) are not considered Dental Service Organizations (DSOs), and dental school administrators do not attend DSO meetings. Dental schools could learn from these meetings as there are many similarities. (School administration provides the management infrastructure, standards of care provide practice guidelines, faculty are like dental employees, etc.) Diverse thought leaders involved in both academic and non-academic practices are needed to address this changing environment.

In the longer term, integrate dental postdoctoral programs into the overall system of U.S. residency education. Many felt that a strong GME program that incorporates postgraduate dental education should be in place. This integration would further the integration of medicine and dentistry. Many also felt that a stronger connection between predoctoral and advanced dental education should exist. Students enter postdoctoral programs with varied levels of preparation as some schools go beyond accreditation standards. It was noted that some residency programs are stand-alone programs or outside dental schools and may be more likely to be disconnected from predoctoral and other residency programs. Some programs are in hospitals, and some are in dental schools; but currently there are not enough slots for all graduates to enroll in a GME-funded program. GME funding is limited, and some postdoctoral programs require tuition, a strain for debt-burdened dental graduates.

A scenario describing a three-year DMD/DDS curriculum and a GME-supported fourth year was discussed. Benefits included a decrease in student debt and a source of income for dental schools. A mandatory fifth year (PGY-1) was also discussed. It was noted that this would be beneficial if it could be done without increasing the level of student indebtedness. It was also noted that the GME program might change or funding may be less available in 2040. As the GME program changes, we may need to rethink how to best fund advanced dental education and how postdoctoral medical and dental education can be integrated. There was some discussion about what the dentist of the future will look like and the role of mid-level providers. Will we need better diagnosticians and/ or better surgeons?

Welcome and facilitate basic oral health education for other health professionals. Incorporating oral health education into the curricula of other health professionals was strongly supported. It was noted that the learning pathway needed to be deliberately planned and not just a random exposure. For this to happen, initiatives to collaborate with and train faculty in other professions would need to occur. Advocacy for this integration will be key. If this recommendation is not followed, our dental silo will continue to keep our profession isolated from the rest of the health care system. Other professions are already starting to step in to fill gaps when people are in need of oral health care. A possible action step to start would be to engage faculty from dental and other health professions programs in a discussion about the benefits and limitations of basic oral health education and have all oral health students communicate and learn with other health professions students. We also need to show other health professions educators how increasing oral health education and patient care can benefit their school and university financially, and we need to advance these concepts into policy platforms of our dental associations. This recommendation involves a paradigm shift to focus on the whole health care team and include settings outside the university, especially when multiple health professions are not located on the same campus as the dental school. This recommendation also needs to apply to faculty development programs and to continuing education programs for clinicians already in practice.

Attendees at this workshop: Michael Reddy, Workshop Leader; Martiza Alford, Elizabeth Andrews, Grishondra Branch-Mays, Linda Centore, Jeanne Chung, Christine Farrell, William Lobb, Lucinda Lyon, William Maas, Phillip Marucha, Rocio B. Quinonez, Nicholas Rodriguez, Richard Stapler, Todd Thierer, Robert Trombly, Mary Truhlar, Jane Weintraub. Recorders: Carla Falcon, Jill York, Heba Elkassaby. 


\section{How Many Dentists Are Needed in 2040}

Marco Vujicic, PhD, the chief economist and Vice President, Health Policy Institute, American Dental Association, led this workshop. The participants discussed the two recommendations made in the "Shrinking Demand for Dental Services" area: downsize dental education; and increase integration with medical and other health professions schools.

The workshop participants discussed the decades-long issue regarding the size of the dentist workforce needed to serve the American people. The approximately $30 \%$ growth in the number of graduates from the expansion in class size at existing dental schools and the opening of 13 new dental schools versus the need for more dentists to serve the population became a not-unexpected topic of vigorous conversation during the workshop and the plenary session when the workshop report was presented. During the workshop, participants reviewed the background data that underlie the recommendation to reduce or downsize the enrollment in dental schools. Shrinkage in the number of graduates being educated would benefit current practitioners, who would have less competition and be in higher demand. On the negative side, dental schools by cutting enrollment would lose significant tuition revenue, and some could close. There is no orderly way for the overall system to reduce enrollment because there is no central guiding body that controls the number of positions in schools. Schools are products of local issues.

Essentially two points of view emerged: 1) reducing class sizes to reduce the number of graduates and bring the size of the workforce into alignment with the demand for care based on the approximately 147-160 million people who seek care as recommended in the report; or 2) repositioning the profession to address the need for care for the approximately 200 million individuals who do not seek oral health care on a regular basis. The former assumes that such factors as changing disease trends to a population with better oral health and changing practice patterns to group practices, mix of personnel, and new technology and preventive methods, as described in the background articles, will lead to a need for fewer dentists. The latter assumes addressing the complex social, economic, and care delivery issues preventing people from seeking care would stimulate demand and need for more dentists. There was some discussion on factors that could drive increasing the demand from those who currently do not utilize dental services such as an expansion of or universal insurance coverage.

The 1995 IOM report, which recommended enrollment should not be increased or decreased without studying manpower issues and monitoring them carefully, needs greater attention than heretofore given to it. While the current study collected comprehensive data by noted experts in the field to project dental manpower needs, from the discussion it was clear that others need to do the same for a consensus to emerge. As noted in the discussion, there is no central body that regulates enrollment levels. Enrollment has ebbed and flowed over time, up and down depending on a number of factors. Such projections are difficult to make and must take into consideration multiple trends as this study has done. While the purpose of the workshops and discussion was not to reach consensus on any of the recommendations, it was clear that the sense of the conference was that there is no more need for enrollment expansion at this time.

Regarding the second recommendation, to increase integration with medicine and other health professions, some viewed it as necessary for dentistry to become part of the health care team and that some lower costs could be realized. However, others felt that going as far as full integration as part of medicine would lose dentistry's identity and have negative effects.

Attendees at this workshop: Marko Vujicic, Workshop Leader; Leon Assael, Howard Bailit, Alexander Carroll, William Davenport Jr., Scott De Rossi, David Gesko, Shannon Green, Mark Latta, Melissa Marlin, Stephen Marshall, John Yamamoto, Linda Zheng, Anthony Ziebert. Recorders: Craig Hirschberg, Rosa Chaviano-Moran.

\section{Research and Scholarship in 2040}

This workshop was led by Dr. Kenneth Kalkwarf, Dean Emeritus of the University of Texas San Antonio School of Dental Medicine. The seven recommendations regarding this component of the project were discussed. Those recommendations were: make research a core mission; recruit research faculty members; increase support for early-stage researchers and students; place increased emphasis on interdisciplinary and collaborative research; address the structural barriers to developing strong research programs; and strengthen CODA research standards 
for dental schools. Another recommendation (prepare students for the new scientific health environment) that was not included in the final report was also discussed.

Make research a core mission. Much of the discussion during this workshop centered around the definition of research. There was general agreement that research is not limited to research funded by the National Institutes of Health (NIH) or even extramurally funded research. Research includes all types of investigations, regardless of the funding mechanisms. Research could be basic, translational, clinical, social or behavioral sciences, educational, or public health in nature.

Some questioned whether all schools needed to have a research focus. Many felt that those that have the infrastructure and are in research universities have a responsibility to do funded research and need to have research as part of their core mission. Others felt that not all schools have the resources or infrastructure to support their own research faculty. Without a critical mass, resources would be wasted. It was clear, however, that discovery and investigations needed to go on. If a critical mass of peer-reviewed research and scholarship is not being conducted in dental schools, then dentistry and oral health would not advance, and dentistry would not remain a profession.

Many, but not all, felt that "research" may not be the right word to use here; rather, a focus might better be placed on scholarship, with the goal that all dental schools should engage in scholarly activity. Boyer's definition of scholarship (in Scholarship Reconsidered: Priorities of the Professoriate) was brought up, referring to four types of scholarship: scholarship of investigation (what is traditionally thought of as research), scholarship of integration, scholarship of application, and scholarship of teaching and learning. Most, but not all, agreed that if the word "research" were changed to "scholarship" in the recommendation, all schools should, and would, be able to play a role in advancing the profession. It was mentioned that NIH-supported schools should have the responsibility of helping other schools get started. They could help jumpstart some of the newer schools by providing virtual or real resources to the table. Teams could be developed between research-intensive schools and other schools just beginning to develop their research activities.

Recruit research faculty members, and place increased emphasis on interdisciplinary and collaborative research. Some participants felt that all schools needed to recruit research faculty members. Others felt that not all schools have the resources or infrastructure to support their own research faculty. Without a critical mass, resources would be wasted, and there would be less efficiency and productivity since science is increasingly a team activity.

Much discussion focused around collaboration and leveraging other schools both within and outside of one's parent institution. For example, many dental schools partner with their sister medical schools. Partnerships between dental schools and disciplines outside of dentistry (e.g., bioengineering and biology) should be strongly encouraged, providing additional external opportunities beyond NIH-funded research. There was also discussion of studies being conducted by faculty and students on campuses and in the community, fostering collaborative research that benefits both dental schools and the community.

Increase support for early-stage researchers and students. There was not a lot of time to discuss this recommendation. It was mentioned that support should cover the entire lifespan; thus, support is needed not just for early stage researchers and students, but also for mid-career and late-stage researchers.

Prepare students for the new scientific health environment. It was mentioned that education in critical thinking and problem-solving skills and the scientific method needed to be further developed in schools. These areas need to become part of the culture of all schools, and education needs to be enhanced in these areas.

Address the structural barriers to developing strong research programs. Resources are the main barrier to this recommendation. These include the length of time to train a researcher, funds required for necessary start-up packages, and support for ongoing research.

Strengthen CODA research standards for dental schools. It was noted that the research standards had recently been changed (going from two to three standards) and additional revisions are currently being considered. CODA is always open to suggestions for changes but needs draft statements to consider and review. Public comment is always solicited for potential changes.

On the research standards, many felt that the most recent change did not go far enough. The standards are written very generically, and expectations are modest with no clear expectation of acceptable outcome levels. There was general agreement that the research standards needed to be strengthened. It was felt that this could be done by changing the wording from research to scholarship, thereby allowing all areas of scholarship to be included. 
Not everyone agreed with this suggestion, however, and some thought it might have the opposite effect. It was also noted that other standards that need to be examined include the standards on evidence-based dentistry (in both the educational section and the patient care section) and the critical thinking and problem-solving standard in the educational section.

Attendees at this workshop: Kenneth Kalkwarf, Workshop Leader; Teresa Dolan, Bruce Donoff, Rena D’Souza, Christopher Fox, Daniel Haas, Connie Kracher, Paul Krebsbach, Phyllis Martina, Laurie McCauley, Peter Polverini, Maria Ryan. Recorders: Daniel Fine, Emi Shimizu.

\section{Challenges Facing the Allied Dental Professions}

Pamela Zarkowski, JD, MPH, Provost and Vice President for Academic Affairs, University of Detroit Mercy, led this workshop, assisted by Colleen Brickle, Dean of Health Sciences, Normandale Community College. The 14 recommendations discussed at the workshop covered four allied dental professions. The recommendations for restorative dental technology education were to 1) require four years of education for all CODA-accredited restorative dental technology programs; 2) move clinical education to digitally equipped, community-based care settings. The recommendations for dental assisting education were to 1) ensure that CODA-accredited dental assisting programs impart knowledge and skills that cannot be obtained on-the-job; 2) prepare graduates for tomorrow's work environments; 3) create opportunities for relevant credit transfers; 4) work to create more standardization among state practice acts. The recommendations for dental hygiene education were to 1) transition to the baccalaureate degree for entry into practice; 2) prepare students for emerging practice environments; 3 ) develop educational pathways for dual dental hygiene-dental therapy degrees; 4) develop additional educational pathways for dental hygienists interested in academics, research, industry, and public health careers; 5) invest in developing diverse faculty for full-time academic careers; 6) increase dental hygienists' role in regulating dental hygiene education and practice. The recommendations for dental therapy education were to 1) increase the availability of dental therapy education; 2) respect local variation and flexibility in dental therapy education models as the field develops.

There was active discussion that covered themes emanating from recommendations for all four fields and for each individual field. Overall, participants pointed out that, instead of referring to these fields as allied dental professionals, the preferred name is "oral health care providers/professionals/practitioners (OHPs)." Such language looks to a future of greater integration of practices into intraprofessional team approaches. A second area of discussion that applied to all four fields was to better consider that these practitioners should be educated with the concept of a "spiral up" model permitting advancement from one to another of the professions. Common to all four professions should be a requirement that students should be educated in accredited programs and not on-the-job training.

The participants discussed the benefits to be accrued if the recommendations were implemented. Several benefits were identified from improved patient outcomes to an emphasis on prevention, from cost-effective quality care to better care for underserved groups, and from strengthening education to greater portability of licensure. To implement the changes, key stakeholders were discussed along with the need for better representation of OHPs on CODA and on state boards of dentistry. There was recognition that organized dentistry through its professional groups would influence changes, but also that organizations outside of dentistry would play a role including dental service organizations, reimbursement from private and government insurance agencies, and the increasing role of improved health literacy by the public. All stakeholders need to be engaged to bring about change.

Recommendations from each of the OHP fields were then discussed. While the intent of the first recommendation for restorative dental technology education is to become four years of education, the discussion instead focused on encouraging the development of CODA-accredited dental technology programs rather than specifying program length. A recommendation for a four-year education may be counterproductive, especially in a field in which formal programs are not flourishing. It is better to keep pathways open from one level of education to the next ("spiral up"), so that careers can progress to a baccalaureate degree and not impede those who may wish to become a restorative dental technologist. This point also applies to the dental assisting field. There was general support for the second recommendation for restorative dental technology: to utilize community-based settings where education in digital methods can be obtained. 
The discussion of the four recommendations for dental assisting education were directed toward strengthening much-needed standardization in the scope of practice for dental assistants and supporting patient safety. The question was raised as to why dental assisting should be permitted to be an on-the-job training profession due to the important role dental assistants play in such areas as infection control and prevention of disease transmission. Having all dental assistants educated in CODA-accredited programs would promote compliance with state and federal infection control guidelines and would lead to more clarity in state practice acts, which now are vastly different from one state to another. Such a move would promote uniformity instead of the current convoluted licensing and credentialing requirements. More standardization might also make advancement to the expanded function dental assistant (EFDA) level more attainable as EFDAs are predicted to play a prominent role in DSOs and large group practices.

One concern was expressed that raising the bar in dental assisting (i.e., requiring graduation from a CODAaccredited programs as the entry level) might inadvertently deter young people from initial entry into the field, especially in rural and dental shortage areas where programs may not be available. Although this unintended consequence could occur, the proposed recommendation was intended to speak to the critical mass. The group's overall opinion was that concern for consumer protection and adherence to high standards of infection control trumped on-the-job training and lower levels of education. Innovative online education programs with externships in existing practices could help address the dilemma. Today, universities and educational consortia often live-stream classes to distant sites.

The six recommendations for dental hygiene education were discussed, noting that many state practice acts limit dental hygiene practice with unnecessary supervisory requirements. For the 200-plus community college dental hygiene programs, articulation agreements with baccalaureate degree programs will become a necessity for a transition to the baccalaureate degree as the entry level for practice. It was noted that, since most of the associate degree programs require prerequisites, these two-year programs actually become three years or more and should lead to a baccalaureate degree. Not to move in that direction is unfair to students and thwarts opportunities for advancement, so there was strong support for this first of the six recommendations.

Given that dental hygienists are now being employed in large group practices and in such alternate settings as pediatric practices and hospitals, recommendations three and four for educational pathways to be developed, including the opportunity for dental therapy training, were also strongly supported. One attendee expressed concern that requiring the baccalaureate degree may result in loss of associate degree programs at community colleges. In response, other group members mentioned that no one is trying to reduce the number of community college programs, and that would not be likely to happen. What was mentioned is a trend toward community colleges' offering baccalaureate degrees through partnerships with universities. This model gives students the degree they have earned, considering the amount of time and money they have put into their education, and reflects the number of credits they have earned through prerequisites and meeting CODA-accredited program requirements. This accelerated model of alignment indeed leverages an educational continuum through the spiral approach from CODA-accredited associate degree programs to attainment of baccalaureate degrees. This seamless transition would facilitate the requirement of the baccalaureate degree as an entry-level credential.

There was strong support to change the wording of the first of the two initial recommendations about dental therapy. The recommendation should not be related to dental hygiene since making dental therapy training available is already included in the dental hygiene recommendations. The first recommendation should be only related to dental therapy and be stated as "Increase the availability of dental therapy programs." During the discussion, however, program length for dental therapy education was also discussed. While four-year programs may dissuade recruitment of some students, there was support for a baccalaureate degree for dental therapy. Educational programs should adhere to the CODA standards, which require at least three years of education and support a spiral up educational concept. However, it was noted that state licensing acts for dental therapists may specify length of educational time or degrees required. Participants noted that expanding dental therapy programs leading to an expansion in the number of dental therapists would increase access to oral health care and meet the needs of underserved populations. Both the workshop discussion and the plenary session ultimately agreed that the recommendation for dental therapy should be stated as "Increase the availability of dental therapy education" and be corrected in the report to avoid confusion. 
Participants commented that there may be some economic roadblocks to some of the recommendations calling for augmented education. Also, using the term "formal" education could lead to disagreement on its meaning. Finally, it was noted that some of the recommendations might lead to pushback from organized dentistry, academicians, and practitioners.

Attendees at this workshop: Pamela Zarkowski, Workshop Leader; Colleen Brickle, Co-Leader; Ann Battrell, Frank Catalanotto, Jan DeBell, Ted DeVries, Debbie Fleming, Jacqueline Fried, Joann Gurenlian, Natalie Kaweckyj, Gayle Mathe, Kim McMahon, Foram Mistry, Diane Peterson, Karl Self, Cheryl Westphal Theile, Karin Trotta. Recorders: Emily Sabato and Vaishali Singhal. 


\section{APPENDIX 2}

\section{Number of New Dental Graduates Needed in 2040}

We used two methods for estimating the number of new dental graduates needed in 2040. The first method was qualitative, and the second was quantitative. The objective was to give a reasonable range for the number of new graduates rather than a precise figure.

\section{Qualitative Estimate}

The primary factors reducing the demand for dental services are, in order of importance:

- Improvements in oral health, especially for the upper-income population that accounts for $65 \%$ of dental practice income. ${ }^{1}$ Significant oral health improvements are also evident in low-income children, and as this young cohort ages, the low-income adult population will also see marked improvements in oral health.

- The decline in per capita working-age adult utilization rates for the privately insured. ${ }^{1}$

- The rapid transition from solo to large-group practices, which will substantially increase the annual average number of patients seen per dentist. ${ }^{1}$

For these and other reasons, the average dentist would have the capacity to see more patients per unit time but would be paid less per patient. ${ }^{1}$ Under these circumstances, dentists would be likely to want to increase the number of patients that they see annually in order to maintain their incomes.

The best estimate of dental utilization suggests that $42 \%$ of Americans use dental services each year. ${ }^{2}$ Based on this percentage, 3,500 new dental school graduates would be needed annually to meet demand in 2040 . Some government surveys suggest that $67 \%$ of the U.S. population uses dental services each year. Those surveys are based on patients' estimates of the care they used during the preceding two years. By contrast, the more reliable $42 \%$ estimate is based on multiple telephone surveys at more frequent intervals. For the sake of completeness, if the $67 \%$ estimate were correct, then 5,000 new graduates would be needed annually. A more detailed explanation for these estimates is provided in an article published in Phase 1 of this project. ${ }^{1}$

\section{Quantitative Estimate}

The American Dental Association (ADA) estimated in 2014 that there would be about 240,000 dentists in 2040, if current trends continue. ${ }^{3}$ A more recent ADA analysis estimates 213,000 dentists, adjusting for expected age and gender changes and assuming the number of new graduates would grow $1 \%$ a year starting in $2020 .{ }^{4}$ Because $30 \%$ of dentists work part-time, the 240,000 figure equals 168,000 full-time equivalent (FTE) dentists. The population in the U.S. in 2040 is expected to be 380 million. ${ }^{5}$ Assuming the percentage of annual dental service users remains at $42 \%$, that would mean 160 million Americans would have one or more visits each year. Assuming that the average dentist sees at least 2,000 patients annually, the number of FTE dentists needed to care for the user population would be 80,000 . This is equivalent to 114,000 full- and part-time dentists.

To determine the number of new dental graduates needed in 2040 , we used the average annual outflow of dentists (through death, retirement, etc.), which is approximately 3\%. ${ }^{3}$ With a base of 114,000 dentists, 3,420 new graduates would be needed to replace the expected outflow of dentists. However, ADA data show that about $12-20 \%$ of the annual inflow of dentists comes from foreign-trained dentists and retired dentists returning to practice - not from new graduates. Assuming 12\% as the best estimate, 410 dentists entering practice in 2040 would not be new graduates. On this basis, about 3,000 new graduates would be needed to replace the outflow of 3,420 dentists. This is a steady-state estimate, which assumes the current supply of dentists is "right-sized" to meet current demand. If this is not the case, even fewer new graduates would be needed.

It is important to note that the estimate of 3,000 new graduates per year assumes no surplus of dentists. If a $30 \%$ surplus of dentists were needed for the dental delivery system to operate efficiently, the number of new graduates needed annually would be about 4,000 . Thus, the quantitative estimate of the number of new graduates needed in 2040 is between 3,000 and 4,000. 


\section{Factors Not Considered}

The estimate of the number of new graduates needed annually is conservative because it does not include the effects of several other supply factors. We assume the following:

- That dental therapists will not markedly increase the supply of dental services by 2040 . This is because only one state, Minnesota, is currently graduating dental therapists, and it will likely be many years before the majority of states approve the practice of dental therapists and produce them in sufficient numbers to influence the supply of dentists.

- That the non-surgical management of dental caries will grow slowly and will have only a limited effect on the productivity of dentists in 2040. This is because many dental schools still do not make this new technology part of their curricula.

- That the provision of primary diagnostic and preventive dental services in medical primary care practices will increase slowly. Currently, $70 \%$ of dental visits include only these two service types. ${ }^{1}$

- That the current policy for licensing foreign-trained dentists will continue.

If any of these assumptions are wrong, even fewer new dental graduates would be needed in 2040.

On the demand side, we estimate that growth of Medicaid expenditures over the next 25 years for lowincome adults will have only a modest effect on total national dental expenditures. ${ }^{6}$ Finally, this analysis presents national estimates for the number of new dental graduates needed in 2040 and does not take into account large regional differences in utilization rates and expenditures.

\section{REFERENCES}

1. Eklund SA, Bailit HL. Estimating the number of dentists needed in 2040. J Dent Educ 2017;81(8 Suppl):eS146-52.

2. Macek MD, Manski RJ, Vargas CM, Moeller JF. Comparing oral health utilization estimates in the United States across three nationally representative surveys. Health Serv Res 2002;37(2):499-522.

3. Munson B, Vujicic M. Supply of dentists in the United States is likely to grow. ADA Health Policy Institute, Research Brief, Oct. 2014. At: www.ada.org/ /media/ADA/Science\%20and\%20Research/HPI/Files/HPIBrief 1014_1.ashx. Accessed 23 June 2016.

4. Munson B, Vujicic M. Dentist earnings were stable in 2015. ADA Health Policy Institute, Research Brief, Dec. 2016. At: www. ada.org/ /media/ADA/Science\%20and\%20Research/HPI/Files/HPIBrief 1216 1.pdf?la=en. Accessed 23 June 2016.

5. Manski RJ, Meyerhoefer CD. Projecting the demand for dental care in 2040. J Dent Educ 2017;81(8 Suppl):eS133-45.

6. Bailit HL. How many dentists are needed in 2040: executive summary. J Dent Educ 2017;81(8):1015-23. 